Research Article

\title{
Simultaneous Determination of Pesticides in Fruits by Using Second-Order Fluorescence Data Resolved by Unfolded Partial Least-Squares Coupled to Residual Bilinearization
}

\author{
Mercedes Villar Navarro, ${ }^{1}$ Miguel Angel Cabezón, ${ }^{2}$ and Patricia C. Damiani $\mathbb{D}^{2,3,4}$ \\ ${ }^{1}$ Departamento de Química Analítica, Facultad de Química, Universidad de Sevilla, C/Profesor García González s/n, \\ Sevilla CP 41012, Spain \\ ${ }^{2}$ Departamento de Química Analítica, Facultad de Ciencias Bioquímicas y Farmacéuticas, Universidad Nacional de Rosario, \\ Suipacha 531, Rosario S2002LRK, Argentina \\ ${ }^{3}$ Instituto de Química Rosario (IQUIR-CONICET), Suipacha 531, Rosario S2002LRK, Argentina \\ ${ }^{4}$ Cátedra de Química Analítica Cuantitativa y Cátedra de Química III, Facultad de Química e Ingeniería del Rosario, \\ Pontificia Universidad Católica Argentina UCA Campus Rosario, Avenida Pellegrini 3314, Rosario S2002LRK, Argentina
}

Correspondence should be addressed to Patricia C. Damiani; damiani@iquir-conicet.gov.ar

Received 5 July 2018; Revised 16 August 2018; Accepted 4 September 2018; Published 16 October 2018

Academic Editor: Qizhen Du

Copyright (C) 2018 Mercedes Villar Navarro et al. This is an open access article distributed under the Creative Commons Attribution License, which permits unrestricted use, distribution, and reproduction in any medium, provided the original work is properly cited.

\begin{abstract}
In the present work, a chemometric-assisted spectrofluorimetric method has been developed for the simultaneous determination of natural fluorescent pesticides, carbaryl, carbendazim, and thiabendazole, in orange and banana. Only a simple extraction with methanol was required as sample pretreatment. Emission-excitation fluorescence matrices were obtained and resolved by using a second-order multivariate calibration method based on unfolded partial least-squares combined with residual bilinearization (U-PLS/RBL) for achieving "second-order advantage." In this way, pesticides were determined in fruits even in the presence of inner filter effects, background interactions, strong spectral overlapping, and unexpected components. U-PLS can cope with effects that cause trilinearity loss such as, inner filter effects, including background in the calibration set; meanwhile, RBL allows to resolve the presence of unexpected components. The extraction technique was validated against a commonly applied technique based on the use of ethyl acetate and sodium sulfate. Besides, results obtained for real samples were statistically compared with those obtained by using HPLC. LODs of $0.038,0.054$, and $0.018 \mathrm{mg} \cdot \mathrm{kg}^{-1}$ and $0.044,0.072$, and $0.020 \mathrm{mg} \cdot \mathrm{kg}^{-1}$ were obtained for carbaryl, carbendazim, and thiabendazole in banana and orange samples, respectively; values were in accordance with the MRLs (Maximum Residue Limits) established by different official control organizations such as National Food Safety and Quality Service (SENASA), Codex Alimentarius (based on Food and Agriculture Organization (FAO) of the United Nations and World Health Organization (WHO), and Environmental Protection Agency (EPA).
\end{abstract}

\section{Introduction}

Pesticides are chemical compounds used to kill, repel, or control certain forms of plants or animal life that are considered to be pests. They can be classified in accordance with their function in insecticides for controlling different varieties of insects, fungicides for preventing the growth of mildew and mushrooms, herbicides for destroying weeds, and disinfectants for avoiding the spread of bacteria and compounds used to control mice and rats. Moreover, they are also used in public health to kill vectors of diseases, such as mosquitoes, and in agriculture, to kill pests that damage crops.

In the present work, three pesticides, carbaryl, carbendazim, and thiabendazole, are studied in fruit samples (banana and orange). They are commonly used for preventing, controlling, or destroying pests in fruits and vegetables, being applied to crops either before or after harvest 
to protect the commodity from deterioration during storage and transport [1-3].

Carbendazim (methyl 1H-benzimidazol-2-ylcarbamate) is a member of the benzimidazole group of fungicides, widely used for the control of fungal diseases in a variety of crops, including cereals, fruits, vegetables, cotton, pasture, turf, and mushrooms. It has been reported to be reproductive and developmental toxicant. It may cause genetic defects and affect fertility in the unborn child. Moreover, the United States Environmental Protection Agency (EPA) has classified carbendazim as Group $\mathrm{C}$ pesticide: Possible $\mathrm{Hu}-$ man Carcinogen [4-6].

Carbaryl (naphthalen-1-yl N-methylcarbamate) is a carbamate pesticide that acts primarily as insecticide, but it can also be considered as molluscicide and acaricide. It is used in corn, soybean, cotton, fruit, nut, and vegetable crops and is also applied in home yards and gardens. Humans are affected via skin contact, ingestion, and inhalation. Carbaryl is a cholinesterase inhibitor. According to the EPA, occupational exposure to carbaryl can result in nausea, vomiting, blurred vision, coma, and difficulty breathing. Taking into account these effects, carbaryl is officially regarded as a type II pesticide: Moderately Hazardous Pesticide. Moreover, regulatory organizations and agencies such as EPA list carbaryl as a suspected carcinogen, endocrine disruptor, and reproductive and developmental toxicant (EPA). Although carbaryl by itself is slightly mutagenic, its reaction with nitrite present in food additives can produce nitrosocarbaryl that is highly mutagenic [5-7].

Thiabendazole ((1H-benzimidazol-2-yl)-1,3-thiazole) is a pesticide belongs to the benzimidazole group which acts mainly as fungicide but also as parasiticide in different crops. Moreover, in banana, it guarantees freshness; in oranges, it is commonly used in waxes applied to the skin of citrus fruits. It is hepatotoxic and is associated with clinically apparent liver injury which can be prolonged and severe [8].

Considering cancer classification, it is likely to be carcinogenic to humans at high doses but not at low doses [6].

Overexposure can cause nausea, vomiting, headache, weakness, drowsiness, and lack of appetite [9].

Because of the widespread use of these agrochemicals in different crops and in consequence in food production, people are exposed to low levels of pesticide residues through their diets. Considering their potential toxicity, involving health effects, they must be used safely, keeping residue levels as low as possible considering the Maximum Residues Levels (MRLs) as the limit. Different local and internationals legislation, all over the world, established the Maximum Residues Limits (MRLs) for each pesticide in each commodity and harvest. A maximum residue limit (MRL) is the highest level of a pesticide residue that is legally tolerated in or on food or feed when pesticides are applied correctly in accordance with Good Agricultural Practice. In our country, Argentina, these limits are fixed by SENASA (National Food Safety and Quality Service) and the Codex Alimentarius International ad hoc related with FAO (Organization of the United Nations For Food And Agriculture) and WHO (World Health Organization). Consumers can trust the safety and quality of the food products they buy, and importers can trust that the food they request will be in accordance with their specifications, so that these legislations protect consumer health $[10,11]$.

Taking into account all these facts and considering the possibility or suspicion of an improper usage of pesticides, it can be concluded that it is important and necessary to determine pesticide usage in each food product or in each harvest.

In general, allowed pesticide residues in fruits are, as it must be expected, very low, requiring in consequence highly sensitive analytical methods for their determination. These methods must be also highly selective since pesticides are determined in complex matrices, in the presence of other unsuspected analytes that usually affect interference, causing adverse effects.

Several methods have been reported in the scientific literature for determining pesticides in fruits and vegetables; most of them are based on chromatographic techniques, involving gas chromatography and high-performance liquid chromatography, in any case coupled with various detectors including the widely used mass spectrometric detector (MS and tandem MS) [12-16].

Recently, ultrahigh-performance liquid chromatography has been widely applied for determining pesticide residues, showing certain advantages in comparison with the classical HPLC, such as high selectivity, sensitivity, and less time of analysis [17-19].

Moreover, other conventional analytical methods have been also published in the scientific literature for determining pesticides, based on micellar electrokinetic capillary chromatography (MEKC) [20-24].

In general, determination of pesticides in complex matrices such as fruit samples by using these conventional analytical methods require tedious sample pretreatments in order to extract the analyte from the bulk of the matrix and then to clean up from other coextracted compounds. Extraction procedures published in the literature are based mainly on liquid-liquid extraction (LLE) [17, 25-27]; matrix solid-phase extraction (MSPE) that involves extraction and clean-up integrated in a single step, requiring less solvent and less time for performing the analysis than the classical methods [28]; and QuEChERS sample preparation technique (quick, easy, cheap, effective, rugged, and safe extraction), which is widely used for determining residue of pesticides in agriculture showing better extraction performance than SPE $[14,18,19,29,30]$.

Recently, another advanced methodology has been proposed as an alternative for traditional chromatographic methods such as electrochemical biosensors [31] and optical biosensors [32].

Molecular imprinted polymers have also been proposed for determining pesticides in fruits and vegetables $[15,33,34]$.

As it has been remarked above, most of the methods used for determining residues of pesticides are based on chromatography. These methods present some advantages such as high sensitivity and selectivity, but at the same time, they have some disadvantages since they require expensive equipment, high amount of toxic, and expensive organic 
solvents; so that they are not environmental friendly and not suitable for analyzing large volumes of samples; moreover, they are time-consuming, complex, and often involve tedious sample pretreatments as it has just been discussed. For all these reasons, these methods seem to be not suitable for developing in simple routine laboratories.

The alternative of applying spectroscopy is required for this purpose, obviously if the analyte can be suitable for determining applying spectroscopic methodologies. In the present work, for example, spectrofluorimetry can be an alternative for analyzing the selected pesticides since they present native fluorescence [35]. Besides, fluorescence presents high intrinsical sensitivity, meanwhile it is not an expensive technique, and instruments are easily available [36]. However, one important disadvantage of fluorescence methods is the presence of potential sample interferences. Tedious sample pretreatments are in consequence required, often affecting the method performance. However, this kind of situation can also be overcome with the aid of multivariate calibration techniques. Typically, spectroscopy can be combined with chemometrics, interferences being mathematically removed [37].

Analytical methods that involve first-order data can resolve the presence of potential interferents only if they are included in the calibration set, so that a lot of calibration samples must be necessary. Any component that is not considered in the calibration stage is often called as an "unexpected component." Moreover, a sample containing unexpected components is marked as an outlier due to the bad fit of its spectrum to the calibration model (first-order advantage), its prediction being not correct [38-40].

On the contrary, second- and higher order-data processed with appropriate multivariate calibration algorithms are able to model unexpected components, allowing the quantitation of the calibrated analytes in a complex multicomponent sample such as fruits, exploiting the so-called "second-order advantage" [41-43].

The purpose of the present work is based on developing a simple, sensitive and selective method, suitable for routine laboratories, based on spectrofluorimetry, generating second-order data assisted by chemometrics, for determining the three selected pesticides, carbendazim, carbaryl, and thiabendazole in banana and orange samples. This system is very interesting from an analytical point of view, taking into account several peculiar features such as (1) a strong spectral overlapping between the analytes and fluorescent matrix backgrounds due to the presence of natural intrinsic fluorescent compounds (fluorophores), both in excitation and emission modes; this background signal can change from sample to sample; (2) a considerable absorbance of fruits background in the selected spectral range, even after dilution, that can be also different among samples; (3) a strong overlapping between thiabendazole excitation spectrum and excitation and emission spectra of carbendazim, suggesting a strong inner filter effect of thiabendazole over carbendazim, as it has been previously discussed in the scientific literature by Piccirili and Escandar [44]; (4) for example, the presence of other unexpected components such as other pesticides. All these particular characteristics must be specially considered for the correct selection of the algorithm used for resolving data.

Fluorescence spectral overlapping, matrix, and inner filter effects, break the trilinearity of the three-way fluorescence data (emission-excitation fluorescence matrices EEMs data), precluding their decomposition in reasonable profiles. Besides, the presence of unexpected components requires the "second-order advantage." So, a suitable algorithm that can cope with all these characteristics must be selected.

Parallel factor analysis PARAFAC can achieve the "second-order advantage" but cannot resolve the lack of trilinearity. To accomplish this purpose, this algorithm needs, at least, the aid of the "standard addition technique," as it has been performed recently in a previous work, for determining pesticides (carbendazim, fuberidazole, and thiabendazole) in lettuce, applying third-order fluorescence data, based on emission-excitation fluorescence matrices measured at different sample dilutions, standard addition, and PARAFAC [45].

In another scientific work, this algorithm was applied for determining only carbendazim in an artificially spiked extract of banana samples. Second-order fluorescence data were resolved using parallel factor analysis, only after exploiting the partial uniqueness property for the PARAFAC $[42,46]$.

However, unfolded partial least-squares U-PLS is a more flexible model that can take into account trilinearity deviations; meanwhile, it can achieve the second-order advantage by coupling to residual bilinearization, RBL, for modeling unexpected signals. The success of this algorithm U-PLS/RBL in this kind of situations: trilinearity loss due to matrix effect and inner filter effect, as well as strong overlapping (near identical spectral profiles among components or components and interferents) and the presence of unexpected components has been discussed in a previous scientific literature [42, 44, 47, 48]. Moreover, this algorithm has been suggested as the appropriate algorithm by Escandar and Olivieri in their review describing the road map for multiway calibration models [49].

Its application avoids the tedious and laborious experimental procedure of standard addition technique, requiring in general only to include a pool of sample background in the calibration set in case of matrix effect $[47,48]$.

This multivariate algorithm has been applied in the present work for predicting the selected pesticides in much complex systems described above such as banana and orange matrices. Its predictive ability for analyzing validation samples, test samples, and real samples has been determined and discussed applying a calibration set performed by including a pool of banana and orange matrix background, respectively, in each case. Figures of merit and accuracy have also been determined and analyzed.

Moreover, the ability of the simple proposed extraction procedure, based only on methanolic extraction, has also been studied and validated by comparison with a commonly used extraction technique based on ethyl acetate and sodium sulfate.

To the best of our knowledge, this is the first attempt to apply this whole method, which involves a simple methanolic 
extraction technique and an analytical determination based on second-order fluorescence data resolved by U-PLS coupled to $\mathrm{RBL}$ involving determination of pesticides in fruits.

\section{Experimental}

2.1. Equipment. All fluorescence measurements were done on a fast scanning Varian Ò Cary Eclipse spectrofluorometer (USA), equipped with two Czerny-Turner monochromators, a xenon flash lamp and connected to a PC microcomputer via an IEEE 488 (GPIB) serial interface. Excitation-emission matrices were recorded in a $1.00 \mathrm{~cm}$ quartz cell. Excitation was scanned in the range 237-305 nm, each $4 \mathrm{~nm}$; meanwhile, emission was scanned from 310 up to $450 \mathrm{~nm}$, each $1 \mathrm{~nm}$, producing a total of $141 \times 18$ spectral data points per sample matrix. Other instrumental parameters were excitation and emission slits: $5 \mathrm{~nm}$, photomultiplier voltage 700 , and scan rate $1500 \mathrm{~nm} \cdot \mathrm{min}^{-1}$. Data were saved in ASCII format and transferred to a microcomputer for processing by multivariate programs.

Absorbance measurements were performed on a Shimadzu Multispec-1501 photodiode array spectrophotometer (Shimadzu Corporation, International Marketing Division, Tokyo, Japan).

High-performance liquid chromatography (HPLC) was carried out using a Waters liquid chromatograph, equipped with a 515 Waters high-pressure pump, a Rheodyne injector, and a diode array UV-visible detector, using (a) column Zorbax SB C18, $4.6 \mathrm{~mm} \times 150 \mathrm{~mm}$ ( $5 \mu \mathrm{m}$ particle size); (b) mobile phase methanol: $\mathrm{H}_{2} \mathrm{O} 50: 50 \mathrm{v} / \mathrm{v}$; (c) flow rate of $1.00 \mathrm{~mL} \cdot \mathrm{min}^{-1}$; (d) temperature maintained at $25 \pm 1^{\circ} \mathrm{C}$; and (e) detection wavelength $280 \mathrm{~nm}$.

2.2. Reagents and Solutions. The following reagents were used in the present work: analytical-grade carbaryl, carbendazim, and thiabendazole (Sigma Aldrich, United State) and methanol (Merck, Darmstadt, Germany).

Pesticide stock solutions of $200 \mathrm{mg} \cdot \mathrm{L}^{-1}$ were prepared by dissolving the compounds in methanol, sonicated for ten minutes, and stored in darkness at $4^{\circ} \mathrm{C}$. Working solutions were prepared by suitable dilutions of the stock solutions with double distilled water.

\subsection{Calibration in the Presence of Matrix}

2.3.1. Calibration Set. A linear relationship between fluorescence intensity and pesticides concentration was previously determined by combining absorbance measurements, fluorescence measurements, and a statistic support based on "lack-of-fit study" calculating the statistic F. Upper limits of $90 \mu \mathrm{g} \cdot \mathrm{L}^{-1}, \quad 100 \mu \mathrm{g} \cdot \mathrm{L}^{-1}$, and $40 \mu \mathrm{g} \cdot \mathrm{L}^{-1}$ were obtained, respectively, for carbaryl, carbendazim, and thiabendazole. As calibration was designed including sample matrix background, a pool of each organic fruit free from pesticides was treated with methanol in accordance with a simple analytical extraction technique performed as follows: organic fruits free from pesticides, purchased in a local organic fruit market, were selected, peeled, and crushed. Samples of 100 grams of pulp were weighed, placed in a $50 \mathrm{~mL}$ glass beaker, treated with $20.0 \mathrm{~mL}$ of methanol, and stirred for 15 minutes. The mixture was left to stand for 30 minutes, and another $20.0 \mathrm{~mL}$ of methanol was added. Then, it was stirred again for another 15 minutes, left to stand for another 30 minutes, and finally centrifuged at $3000 \mathrm{rpm}$ for 15 minutes. The supernatant was separated and filtrated. This methanolic extract can be considered as a blank, involving only the signal of the matrix background, since fruits free from pesticides were used. Suitable known amounts of pesticide working solutions were mixed with a suitable volume of the pool of methanolic fruit extract, usually $0.100 \mathrm{~mL}-0.200 \mathrm{~mL}$ for banana and orange, respectively, in accordance with spectral signal and diluted with methanol to $10.00 \mathrm{~mL}$ in a volumetric flask in order to obtain concentrations within the linear calibration ranges, good sensitivity and appropriate background signals. The set was prepared in accordance with a Placket-Burman experimental design containing the analytes within the linear concentration ranges, modified by including a blank, three samples containing, each of them, only one pesticide at a mean concentration, and a sample containing the three analytes at a middle concentration [50, 51]. All calibration solutions were prepared in triplicate. Emission-excitation matrices were obtained as it has just been previously described, measured in random order, and processed applying the selected algorithms.

2.3.2. Validation Set Samples. In order to prepare samples useful for validating the predicting ability of the method including background in the calibration set, methanolic extracts of the same organic fruits pool samples applied in the calibration set (i.e., the same matrix background) were artificially spiked with solutions of pesticides within the linear calibration ranges. Emission-excitation matrices were recorded in random order and resolved by applying the selected algorithms.

2.3.3. Test Samples. Then, other organic fruit samples also free from pesticides, and different from those used in the calibration and validation sets, were treated by applying the methanolic extraction technique as it has been described in Section 2.3.1, methanolic extracts being artificially spiked with the analytes following the calibration concentration ranges. Emission-excitation matrices were obtained as it has just been described and resolved by applying the selected algorithms using calibration in the presence of matrix.

\subsection{Spiked Fruit Samples: Recovery Study-Validation of the} Extraction Technique and of the Whole Method. One hundred grams of a pool of fruit pulp free from pesticides were weighed, crushed, and fortified with appropriate amounts of the analytes, mainly in accordance with the maximum residue limits as well as the Limits of Detection of each pesticide. Samples were left to stand for 24 hours, and then extraction with methanol was performed as it has been detailed in Section 2.3.1. Finally, pesticide concentrations were determined by applying the present method. Recoveries 
were analyzed and also compared with the values obtained using a classical extraction technique based on the use of ethyl acetate and sodium sulfate, in order to validate the present proposed extraction technique.

Another one hundred grams of the same pool of fruit pulp, free from pesticides used for applying methanol extraction technique, were fortified with the same amounts of pesticides and treated by applying a classical extraction technique based on the use of ethyl acetate and sodium sulfate [46].

One hundred grams of the same pool of fruits pulp free from pesticide were weighed, put in a $100 \mathrm{~mL}$ glass beaker, spiked with the same amounts of pesticides used in methanol extraction technique, and treated with $10.0 \mathrm{~g}$ of anhydrous sodium sulfate and $20.0 \mathrm{ml}$ of ethyl acetate, mixed, stirred for $10 \mathrm{~min}$, left to settle down for $20 \mathrm{~min}$, and filtrated. The procedure was repeated by treating the solid with another $10.00 \mathrm{ml}$ of ethyl acetate, mixed, stirred, left to settle down, and filtrated again. Supernatant was collected and joined with the previous one. The beaker was rinsed twice with $5 \mathrm{ml}$ of ethyl acetate. $10.00 \mathrm{ml}$ of the filtrate was evaporated to dryness under a stream of nitrogen. The residue was dissolved in $10.00 \mathrm{ml}$ of methanol in a volumetric flask. The same dilution of the extract was performed and proceeded as described above for determining pesticide concentrations. Recoveries were obtained and compared with those registered using methanol as extractant.

2.5. Real Fruit Samples. Finally, bananas and oranges purchased in different markets located in the city of Rosario, Argentina, were analyzed. Fruits were peeled and crushed. One hundred grams of pulp were weighed and treated with methanol for extracting the pesticides as it has been described above. Emission-excitation matrices were recorded and resolved applying the selected algorithm for quantifying the analytes. Results were compared with those obtained by using the adapted high-performance liquid chromatography (HPLC) technique described in Section 2.6, following the parameters defined in Section 2.1 [16].

2.6. Chromatographic Procedure. Standard solutions were prepared by suitable dilution in the mobile phase (methanol: $\mathrm{H}_{2} \mathrm{O} 50: 50 \mathrm{v} / \mathrm{v}$ ) of stock solutions in accordance with the linear calibration range up to $200 \mathrm{ug} \cdot \mathrm{mL}^{-1}$ for carbendazim and thiabendazole and $100 \mathrm{ug} \cdot \mathrm{mL}^{-1}$ for carbaryl. Methanolic fruit extracts were conveniently diluted with the same mobile phase. Both, standard solutions as well as methanolic fruits samples extracts were filtered using a nylon filter and then injected following the parameters described in Section 2.1. Absorbance was recorded at $280 \mathrm{~nm}$, detecting carbendazim, thiabendazole, and carbaryl at 4.2, 5.8, and 8.5 minutes, respectively.

2.7. Software. All routines employed in this paper were written in MATLAB 7.0. [52] [MATLAB 7.0, The Mathworks, Natick, Massachussets, USA, 2007]. For assistance, users can read the document "mvc2_gui_manual.pdf" and Chemom. Intell. Lab.
Syst. 96 (2009) 246-251 written by Olivieri et al. Department of Analytical Chemistry University of Rosario Argentina [53]. U-PLS/RBL is available at http://www.chemometry.com/, including a graphical user interface $[41,42,53]$.

\section{Results and Discussion}

3.1. Spectral Characteristics: Selection of a Suitable Method of Analysis. Considering that the three analytes of interest present native fluorescence, this spectral characteristic has been exploited for their determination.

Analyzing Figure 1, which shows the fluorescence emission and excitation spectra of carbendazim (CZ) $100 \mu \mathrm{g} \cdot \mathrm{mL}^{-1}$, thiabendazole (TIA) $40 \mu \mathrm{g} \cdot \mathrm{mL}^{-1}$, and carbaryl (CR) $90 \mu \mathrm{g} \cdot \mathrm{mL}^{-1}$ in methanol, it can be noticed a strong overlapping in both dimensions for all the analytes.

In particular, thiabendazole shows a considerable excitation at the spectral range $280-320 \mathrm{~nm}$, partially coincident to the excitation and emission ranges of carbendazim (Figure 1). This fact allows the reader to conclude that an inner filter effect is caused from thiabendazole over carbendazim when both pesticides are simultaneously present in samples. As it can be noticed in Figure 2, the fluorescence intensity of carbendazim (CZ) is going to be different in presence and absence of thiabendazole (THB), as it has just been discussed in a previous scientific work by Piccirilli and Escandar [44].

These spectral characteristics, strong overlapping and inner filter effect, which affect the intensity and also the shape of fluorescence spectra, prevent the simultaneous determination of the present analytes by using a direct conventional spectrofluorimetric method, even in a simple methanolic matrix containing only the three pesticides.

It can be expected that the situation will be worst in complex fruit matrices. Banana as well as orange matrices present a native fluorescence, due to the presence of natural fluorescent compounds (fluorophores). These unexpected compounds seem to vary from sample to sample in quantity and in quality, but in general, they show strong overlapped fluorescence spectra to those belonging to the analytes, both in excitation and emission dimensions. Banana background shows an excitation band near 250-300 $\mathrm{nm}$ with a maximum closely to $270-280 \mathrm{~nm}$ strong overlapped mainly with carbendazim and carbaryl excitation signals; similar situation presents orange background, causing these facts, in the excitation mode an intensity decrease of the incident light (excitation inner filter effect).

Meanwhile, in the emission wavelength selected range, it can be noticed a strong spectral overlapping between these backgrounds and the three analytes (Figure 3 ).

Moreover, banana and orange sample backgrounds absorb radiation along the selected wavelength ranges. Banana background shows a considerable absorbance, mainly in the excitation wavelength range, strong overlapped with carbaryl and carbendazim absorbance, and in consequence with excitation mode; on the contrary, orange backgrounds show a considerable absorbance along excitation and emission modes, as it can be noted in Figure 4 . 


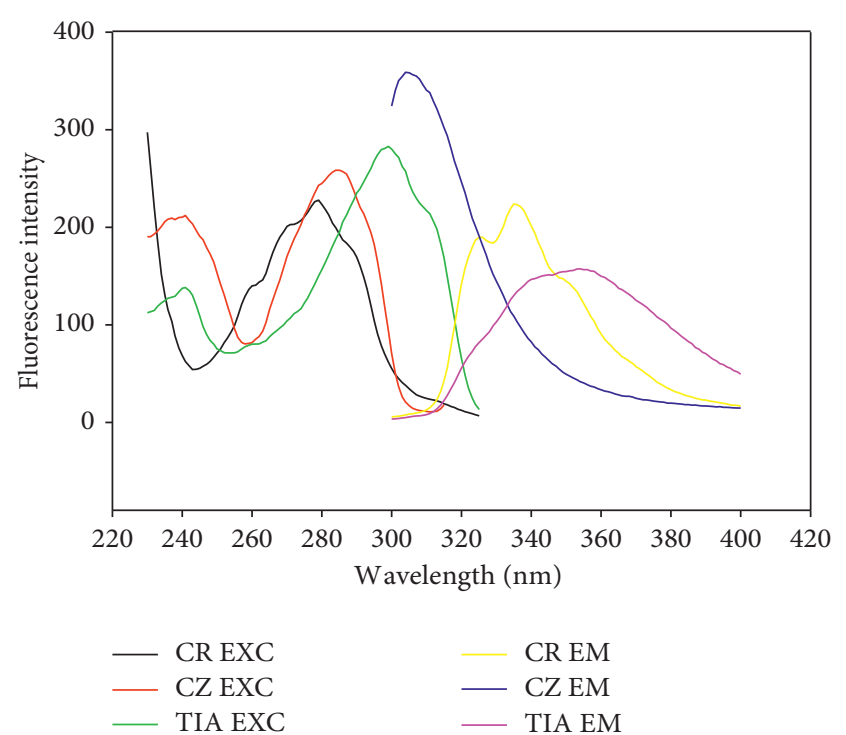

Figure 1: Fluorescence excitation and emission spectra of pesticides.

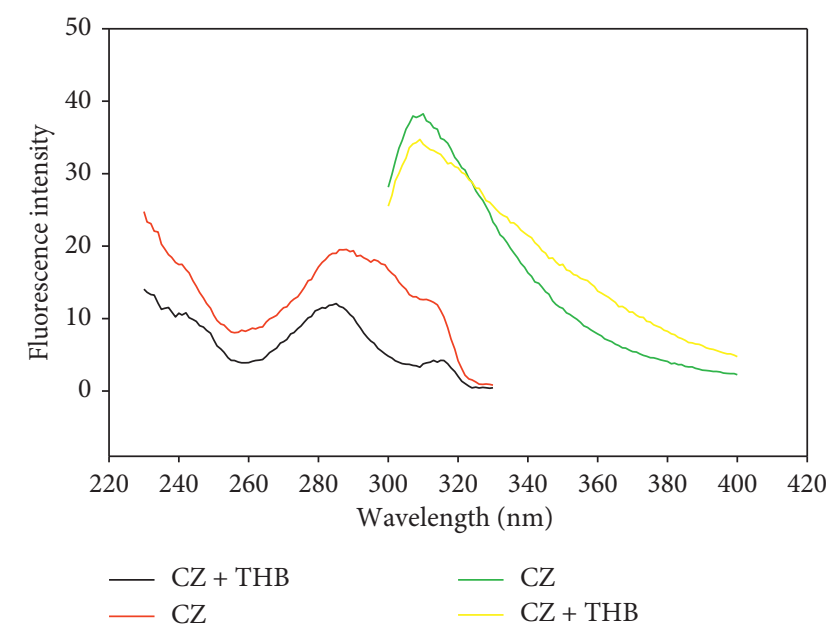

Figure 2: Excitation and emission spectra of carbendazim in the presence and absence of thiabendazole.

These effects can be decreased but not avoided by suitable sample dilutions.

Sample dilutions must be performed trying to minimize the background signal but maintaining a reasonable and sensitive analytes spectral signal, suitable for measurements.

The situation could be more serious if samples contain more unexpected compounds, such as other pesticides, that could also absorb in the present spectral range or show similar fluorescence characteristics.

It can be concluded that these particular spectral characteristics of the fruit matrices also contribute to prevent the use of direct conventional spectrofluorimetric methods for determining the present pesticides. In any case, tedious sample pretreatments must be required trying to isolate the analytes from the different kinds of interferences. Fortunately, this kind of situation in analytical chemistry could be surely

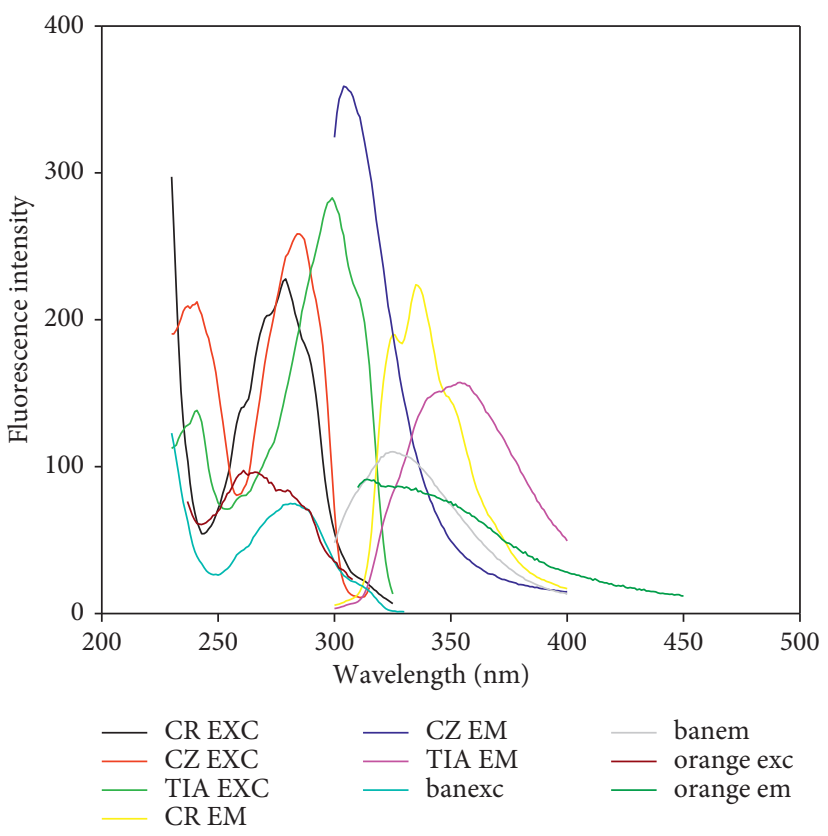

FIgURE 3: Fluorescence emission and excitation spectra of pesticides and fruit matrices.
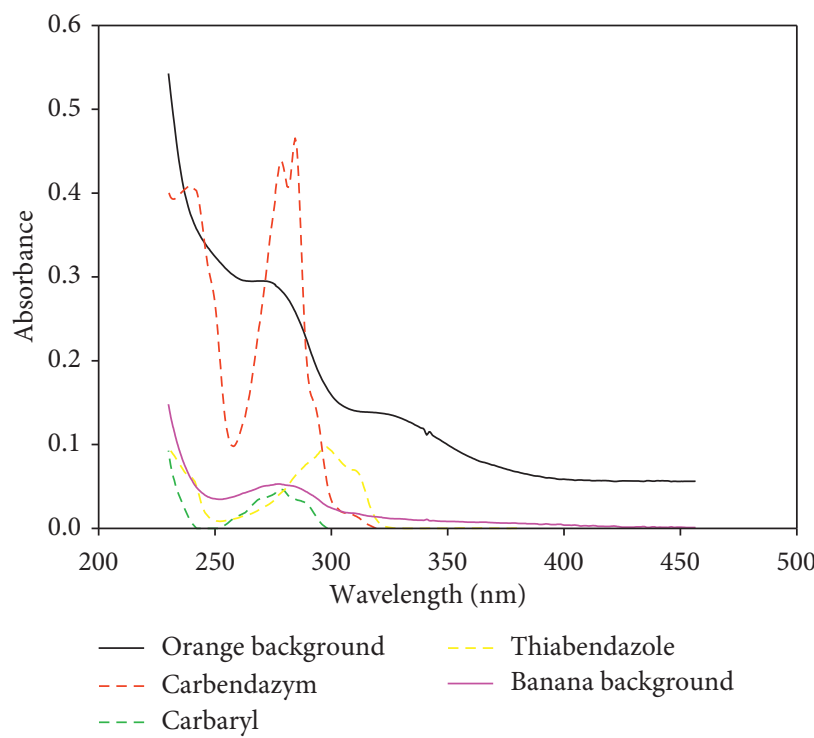

Figure 4: Absorbance spectra.

resolved with the help of chemometrics, interferences being mathematically removed. As it has been discussed in the scientific literature, features like strong spectral overlapping in the excitation and emission modes among the corresponding analytes as well as between analytes and natural fluorophores, the presence of inner filter effects, the presence of matrix effect from banana and orange backgrounds, and the presence of unexpected components require to register higher-order data for obtaining a suitable solution by chemometrics aid. This kind of data - higher order data — can be resolved by applying algorithms that achieve the "second-order advantage" closely related with the matrix complexity. This advantage allows the 
determination of analytes even in the presence of components that are not considered in the calibration step (unexpected components). Moreover, this higher-order data improve better sensitivity and selectivity in comparison with firstorder ones, since they introduce more measurement dimensions or modes and in consequence more sensors [41-43].

For this purpose, in the present work, a spectrofluorimetric method based on second-order fluorescence data such as emission-excitation fluorescence matrices was developed. Matrices data were obtained in the spectral ranges mentioned above, selected considering the maximum signals of each analytes and avoiding the Rayleigh scattering (Figure 5). Finally, data were resolved by applying second-order algorithms.

The next step involved the selection of suitable algorithms.

This particular spectral characteristics of the present work, mentioned above, which affect the intensity and/or shape of fluorescence spectra of the analytes, cause a loss of trilinearity condition, generating nontrilinear data. In previous scientific studies, it has been concluded that it is very important to determine the cause of trilinearity loss, in order to select the suitable algorithms for the successful processing of multidimensional data. [42, 47, 49]. According to these facts, in the present system, the threeway data array becomes nontrilinear due, first of all, to the inner filter effect from thiabendazole over carbendazim, to the strong spectral overlapping in both modes between analytes and analytes and natural fluorophores present in fruits, and to the matrix effect due to the absorbance in the spectral range causing inner filter effect in both modes, hence precluding the use of PARAFAC, since this algorithm requires trilinearity in the data, considering a unique solution; it means, a single profile in each data dimension in all samples should be registered for a calibrated component; meanwhile, in the presence of inner filter effect, several different profiles in each dimension are obtained $[42,47,48]$. As it has been recently discussed in a new manuscript written by Escandar and Olivieri, when the socalled matrix effect (interaction between background components and analytes which are sample dependent) is present, PARAFAC could be used only by using the standard addition technique [49].

In fact, in the scientific literature, some pesticides were determined in complex matrix samples such as vegetables (lettuce) by combining PARAFAC and standard addition [45].

However, Escandar and Olivieri [49] remarked that this tedious experimental strategy can be replaced by treating the nontrilinear fluorescence data, due to matrix effect, inner filter effect with U-PLS (unfolded partial least-squares). This algorithm can cope with the loss of trilinearity, but it is not able to resolve the presence of unexpected components not considered in the calibration set as PARAFAC can do, achieving the "second-order advantage per se." For this purpose, U-PLS must be coupled to residual bilinearization (RBL). Under this condition, the algorithm U-PLS coupled to RBL should be able to resolve all the situations present in this case [49].
Typically, for inner filter effects in luminescence spectroscopy, mainly for second-order data as emissionexcitation fluorescence matrices, the scientific literature suggests that unfolded partial least-squares (U-PLS) combined with residual bilinearizaton (RBL) for achieving the "second-order advantage" is the appropriate algorithm [42], always designing the calibration set taking into account the need of modeling the inner filter effects. U-PLS models analyte behaviour, meanwhile RBL takes care of the background signal. In the present case, the inner filter from thiabendazole over carbendazim was considered including the analytes in the calibration set. Meanwhile, the matrix effects originated by the interactions between the analytes and sample background, mainly for carbendazim and carbaryl, required to include the sample background in the calibration set. The inclusion of the background in the calibration can cause a loss of the trilinearity condition, due to spectral variations from sample to sample, also preventing the application of PARAFAC.

Although fruit background has been included in the calibration set, the "second-order advantage" is still necessary since fruit background composition is sampledependent. In Figure 6, excitation-emission fluorescence matrices for different fruit samples free from the analytes of interest (background signals) are shown. It can be noticed that spectral background signal is sample-dependent.

In the scientific literature, other algorithms, such as PARAFAC2 and MCR-ALS, have been proposed for resolving trilinearity deviations, but only when the effects occur on emission mode or on excitation mode, but not on both modes like in the present case [42]. Moreover, the second-order algorithm BLLS/RBL could not be applied either, because an incomplete calibration was performed, resulting in an incomplete knowledge of calibration constituents, since sample background was included in the calibration set [42].

In conclusion, the second-order algorithm U-PLS/RBL can be applied even when trilinearity deviations, incomplete calibration, and unexpected components are present.

\subsection{Multivariate Calibration Results}

3.2.1. Calibration in Presence of Matrix: Analysis of Validation Samples and Test Samples-Evaluation of the Method Determination Stage. All these peculiar characteristics of the present systems that have been discussed above preclude the use of an external calibration and suggest that orange and banana matrices must be included in the calibration set.

So, as it has been described in Experimental, calibration was performed including fruit backgrounds. Then, a set of validation samples were prepared, using the same fruit pool samples applied in the calibration sets, maintaining the same background matrices. Four latent variables (A) were required for all the analytes in both banana and orange samples, for explaining $99 \%$ of variability present in the calibration set, estimated by using leave-one-out cross validation, according to Haaland and Thomas criterion [54]. The number of unexpected components, calculated 


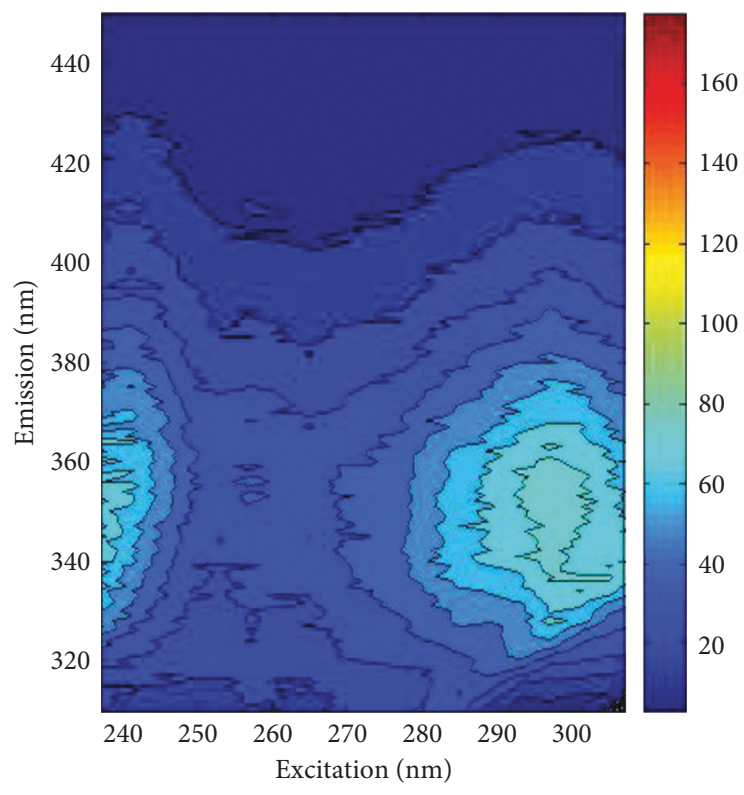

(a)

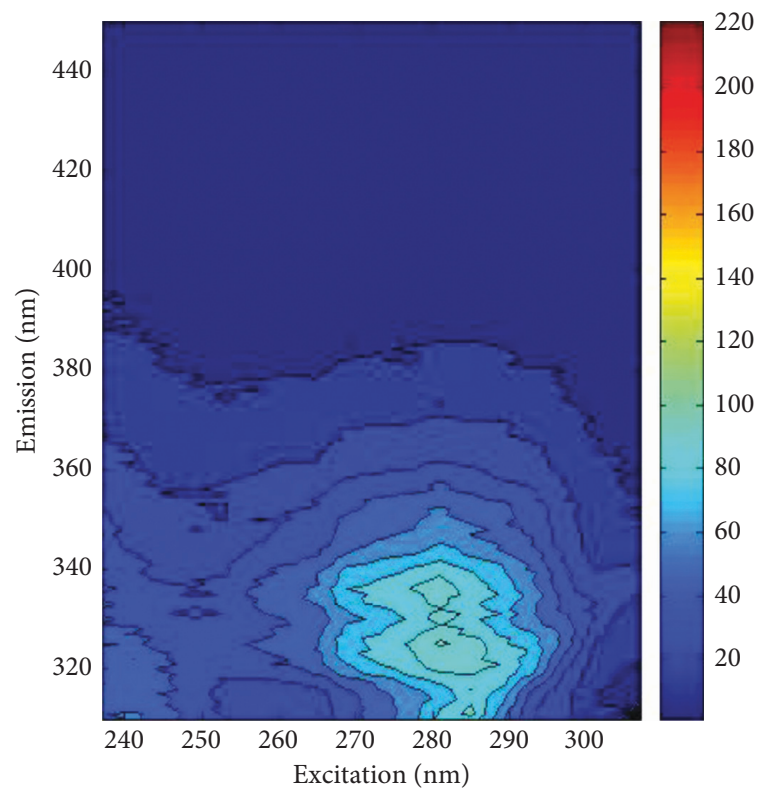

(b)

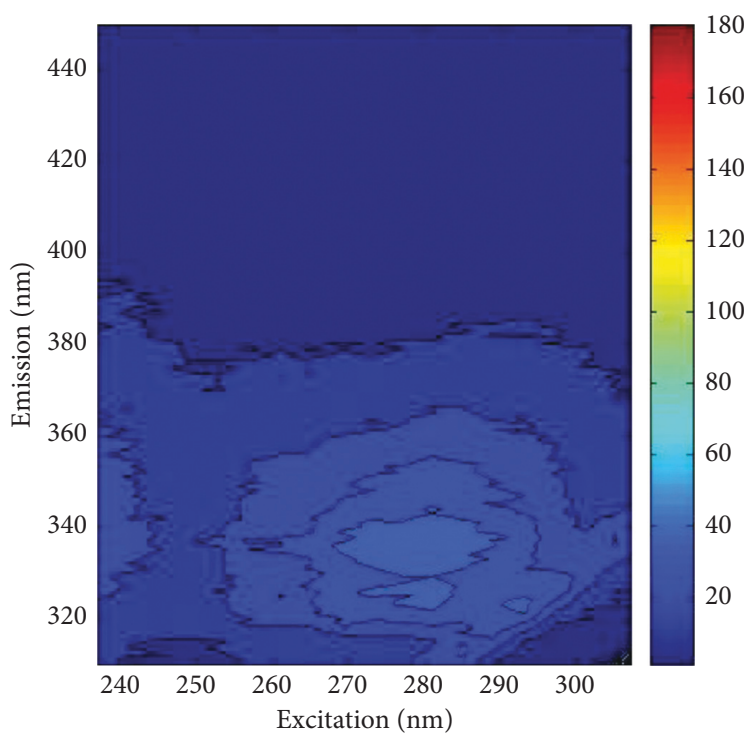

(c)

FiguRE 5: Emission-excitation fluorescence matrices of pesticides in methanol: (a) thiabendazole $30 \mu \mathrm{g} \cdot \mathrm{mL}^{-1}$, (b) carbendazim $80 \mu \mathrm{g} \cdot \mathrm{mL}^{-1}$, and (c) carbaryl $60 \mu \mathrm{g} \cdot \mathrm{mL}^{-1}$.

considering error analysis, was $0\left(N_{\mathrm{unx}}=0\right)$ as it was expected taking into account that validation samples composition was identical to that used in the calibration set, the "second-order advantage" not being necessary [42, 55]. Satisfactory results were obtained for the three analytes with RMSEP values of $1.9,1.5$, and $0.7 \mu \mathrm{g} \cdot \mathrm{L}^{-1}$ and REP $\%$ of $1.5,1.3$, and 0.6 for carbaryl, carbendazim, and thiabendazole, respectively, in banana samples. Meanwhile, RMSEP values of $1.8,1.6$, and $1.0 \mu \mathrm{g} \cdot \mathrm{L}^{-1}$ and $\mathrm{REP} \%$ values of $1.6,1.4$, and 0.9 were obtained for orange samples (Table 1$)$. RMSEP calculated as $\left[(1 / I) \sum_{1}^{I}\left(c_{\text {nom }}-c_{\text {pred }}\right)^{2}\right]^{1 / 2}$, where $I$ is the number of samples, and REP\% calculated as $(100 / \bar{c})\left[(1 / I) \sum_{1}^{I}\left(c_{\text {nom }}-c_{\text {pred }}\right)^{2}\right]^{1 / 2}, \bar{c}$ being the mean calibration concentration, are statistical tests suitable for checking precision and accuracy; their satisfactory results indicate good agreement between nominal and predicted concentration values ( $c_{\text {nom }}$ and $c_{\text {pred }}$ ).

Satisfactory values were also obtained for other figures of merit as sensitivity (SEN), expressed as the ratio between the arbitrary units of fluorescence and concentration (corresponding to the net signal of the analyte at unit concentration) and analytical sensitivity $\left(\gamma_{n}\right)$, calculated as the ratio between the sensitivity (SEN) and the instrumental noise level and the inverse of analytical sensitivity $\left(\gamma_{n}^{-1}\right)$, which indicates the minimum difference in concentration which can be measured (Table 1) $[56,57]$. Ordinary detection limits 


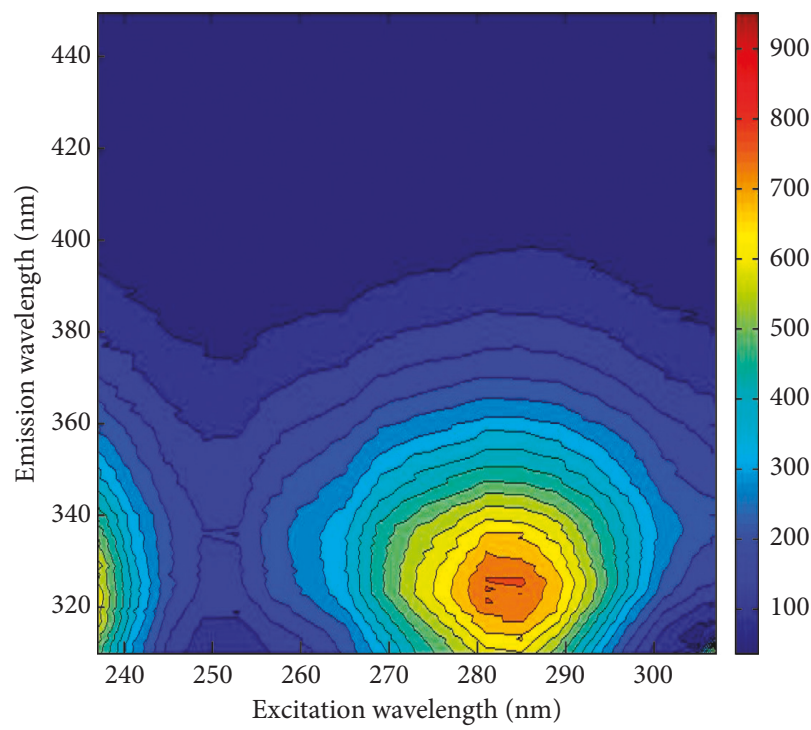

(a)

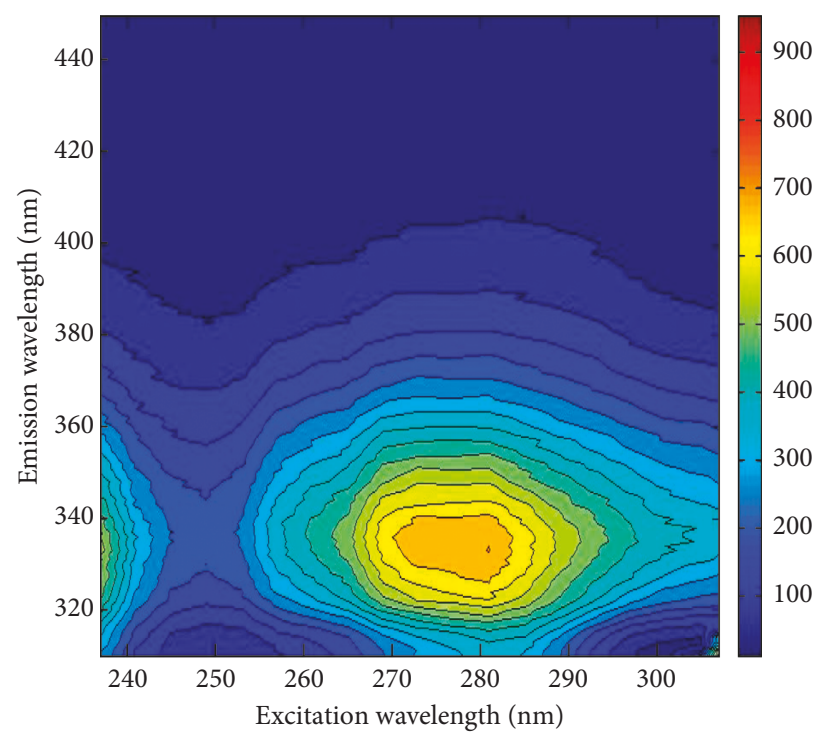

(c)

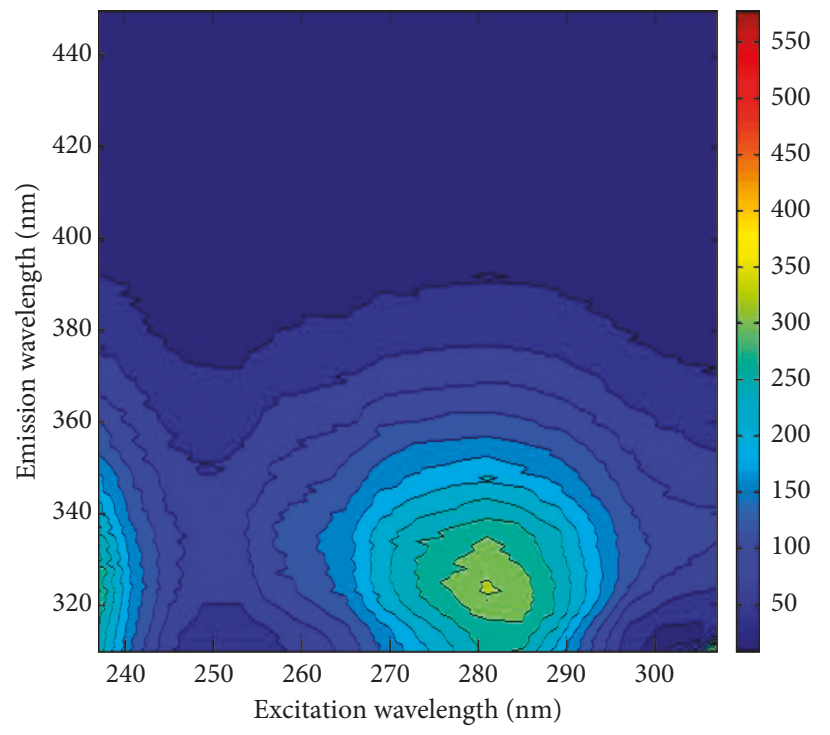

(e)

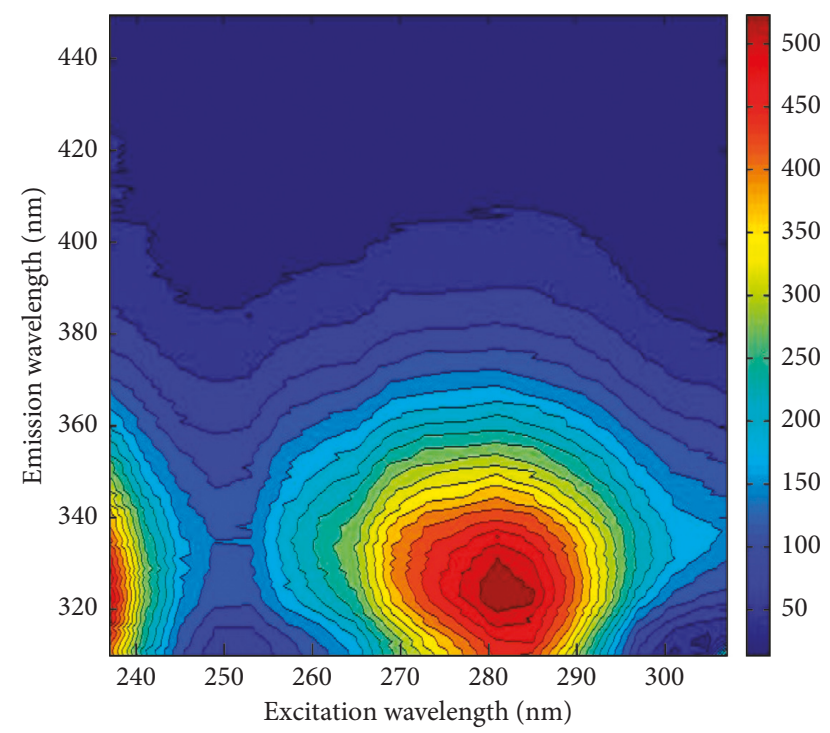

(b)

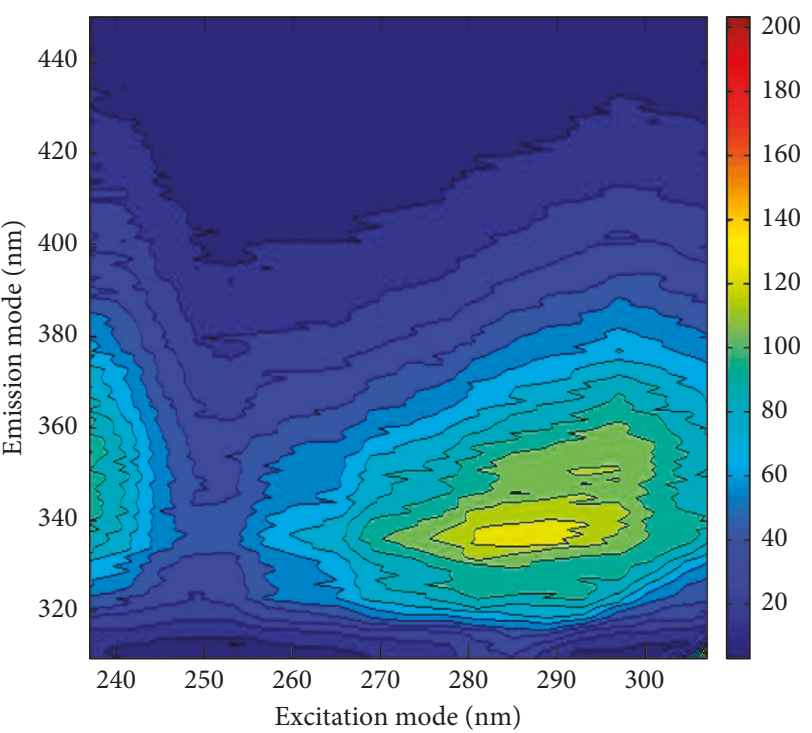

(d)

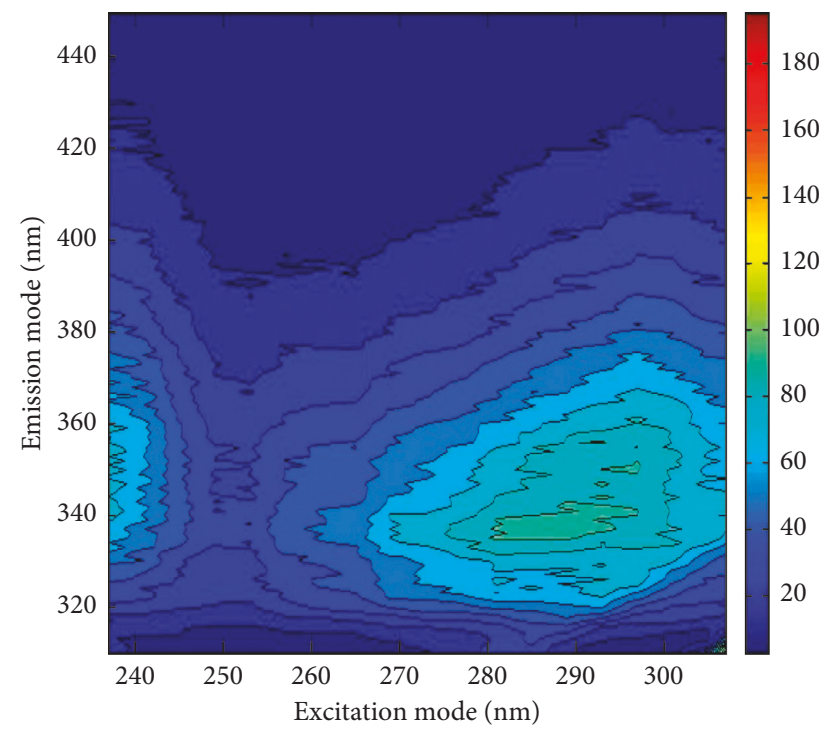

(f)

FIGURE 6: Emission-excitation fluorescence matrices of $(\mathrm{a}-\mathrm{c})$ banana backgrounds and $(\mathrm{d}-\mathrm{f})$ orange backgrounds. 
TABLE 1: Calibration in the presence of matrix: validation samples analysis applying U-PLS/RBL.

\begin{tabular}{|c|c|c|c|c|c|c|c|c|}
\hline \multicolumn{3}{|c|}{ Carbaryl $\mu \mathrm{g} \cdot \mathrm{L}^{-1 \dagger}$} & \multicolumn{3}{|c|}{ Carbendazim $\mu \mathrm{g} \cdot \mathrm{L}^{-1 \dagger}$} & \multicolumn{3}{|c|}{ Thiabendazole $\mu \mathrm{g} \cdot \mathrm{L}^{-1 \dagger}$} \\
\hline Added & Found banana & Found orange & Added & Found banana & Found orange & Added & Found banana & Found orange \\
\hline 0 & $3.1(2)$ & $3.0(2)$ & 0 & $2.1(1)$ & $3.1(2)$ & 0 & $1.1(2)$ & $2.1(1)$ \\
\hline 60 & $62.2(2)$ & $63.3(2)$ & 0 & $0(4)$ & $1.0(1)$ & 20 & $20.1(1)$ & $21.0(1)$ \\
\hline 0 & $0(1)$ & $1.0(1)$ & 75 & $74.3(2)$ & $76.1(1)$ & 20 & $20.2(1)$ & $19.1(1)$ \\
\hline 30 & $28.3(1)$ & $30.1(1)$ & 50 & $50.1(3)$ & $49.0(1)$ & 0 & $2.0(2)$ & $3.1(2)$ \\
\hline 90 & $90.4(2)$ & $89.5(1)$ & 100 & $102.3(3)$ & $99.1(1)$ & 40 & $40.1(1)$ & $38.0(1)$ \\
\hline 30 & $83.4(2)$ & $32.4(1)$ & 100 & $99.1(3)$ & $102.3(4)$ & 40 & $41.3(1)$ & $39.0(2)$ \\
\hline 90 & $91.5(2)$ & $92.1(1)$ & 50 & $50.4(5)$ & $49.1(3)$ & 20 & $22.2(4)$ & $21.0(3)$ \\
\hline 60 & $61.6(1)$ & $62.3(1)$ & 75 & $72.3(2)$ & $74.2(4)$ & 40 & $40.1(1)$ & $40.2(2)$ \\
\hline$R M S E P \mu \mathrm{g} \cdot \mathrm{L}^{-1}$ & 1.9 & 1.8 & & 1.5 & 1.6 & & 0.7 & 1.0 \\
\hline REP \% & 1.5 & 1.6 & & 1.3 & 1.4 & & 0.6 & 0.9 \\
\hline \multirow{2}{*}{$L O D \mu \mathrm{g} \cdot \mathrm{L}^{-1}$} & 1.9 & 2.2 & & 2.7 & 3.6 & & 0.9 & 1.0 \\
\hline & 4.0 & 4.0 & & 6.0 & 7.0 & & 2.8 & 3.0 \\
\hline \multirow{2}{*}{$L O D \mathrm{mg} \cdot \mathrm{kg}^{-1}$} & 0.038 & 0.044 & & 0.054 & 0.072 & & 0.018 & 0.020 \\
\hline & 0.088 & 0.088 & & 0.120 & 0.144 & & 0.056 & 0.060 \\
\hline $\operatorname{SEN}$ AFU $\left(\mu \mathrm{g} \cdot \mathrm{L}^{-1}\right)^{-1}$ & 4.3 & 4.1 & & 3.5 & 3.2 & & 15.0 & 14.0 \\
\hline$\gamma{\mathrm{L} \mu \mathrm{g}^{-1}}^{-1}$ & 1.7 & 1.6 & & 1.3 & 1.2 & & 4.8 & 4.3 \\
\hline$\gamma^{-1} \mu \mathrm{g} \cdot \mathrm{L}^{-1}$ & 0.6 & 0.6 & & 0.8 & 0.8 & & 0.2 & 0.2 \\
\hline
\end{tabular}

RMSEP $=$ root mean square error of prediction. REP $\%=$ relative error of prediction. ${ }^{\dagger}$ Average concentration of three determinations. Standard deviation in parenthesis. Latent variables $A=4$ for all the analytes. Number of unexpected components $N_{\text {unx }}=0 . L O D$ calculated as an interval [58] SEN= sensitivity expressed as the ratio between the arbitrary units of fluorescence and concentration (corresponding to the net signal of the analyte at unit concentration; $\gamma=$ analytical sensitivity calculated as the ratio between the sensitivity (SEN) and the instrumental noise level; $\gamma^{-1}=$ inverse of analytical sensitivity is the minimum concentration difference which can be measured).

(LODs) were also calculated as has been proposed by Allegrini and Olivieri [58].

LODs minimum values $\left(\mathrm{LODs}_{\min }\right)$ of $1.9,2.7$, and $0.9 \mu \mathrm{g} \cdot \mathrm{L}^{-1}$ corresponding to $0.038,0.054$, and $0.018 \mathrm{mg} \cdot \mathrm{kg}^{-1}$ and LODs maximum values $\left(\mathrm{LODs}_{\mathrm{max}}\right)$ of $4.0,6.0$, and $2.8 \mu \mathrm{g} \cdot \mathrm{L}^{-1} \quad$ corresponding to $0.088,0.120$, and $0.056 \mathrm{mg} \cdot \mathrm{kg}^{-1}$ were obtained in banana samples; meanwhile, LOD minimum values of $2.2,3.6$, and $1.0 \mu \mathrm{g} \cdot \mathrm{L}^{-1}$ corresponding to $0.044,0.072$, and $0.020 \mathrm{mg} \cdot \mathrm{kg}^{-1}$ and LOD maximum values of $4.0,7.0$, and $3.0 \mu \mathrm{g} \cdot \mathrm{L}^{-1}$ corresponding to $0.088,0.144,0.060 \mathrm{mg} \cdot \mathrm{kg}^{-1}$ were obtained in orange samples for carbaryl, carbendazim, and thiabendazole, respectively (Table 1). These values were in accordance with the correspondent MLR values established by different official legislations mainly for carbendazim and thiabendazole. For pesticide carbaryl, there is a peculiar situation, since for the Codex Alimentarius and SENASA legislations no MRL value is associated with the commodity banana; similar situation is presented by the European Union Legislation for determining LOD of carbaryl in oranges; usually a "default value" is assigned corresponding to the limit of detection of the reference method (0.01-0.05 $\mathrm{mg} \cdot \mathrm{kg}^{-1}$ ) as in the case of EU (EU 1096/2014 MRLs for carbaryl, procymidone, and profenofos in/on certain products) [59]; or another legislation is considered. Meanwhile, an EU harmonized value is established for carbaryl in banana corresponding to 0.05 and $0.1 \mathrm{mg} \cdot \mathrm{kg}^{-1}$. This implies that the EU member and nonmember states (Norway and Switzerland) recognize the harmonized level as the import tolerance; except where the nonmember states have a higher level $1 \mathrm{mg} \cdot \mathrm{kg}^{-1}$, in which case that value applies as an import tolerance (MRL) (Table 2) [60].

Then, fruit samples different from those used in the calibration and validation sets, it means test samples, were treated as it has been described in Section 2.3.1 and added with the analytes at appropriate random concentrations, in order to predict the ability of the proposed algorithm $\mathrm{U}-\mathrm{PLS} / \mathrm{RBL}$ to determine the analytes not only in complex matrices but also even when the background signals change from sample to sample. The number of latent variables were four $(A=4)$ for all the analytes in both fruit samples, as in calibration and validation samples, modeling the analytes and background interactions [54].

The number of unexpected components $\left(N_{\text {unx }}\right)$ was determined by comparing the U-PLS prediction residues values before and after applying RBL. One, two, or three components ( $N_{\text {unx }}=1,2$, or 3 ) seemed to be necessary for stabilizing these residues, depending on the sample spectral features [42]. Although, the fruit matrices were included in the calibration sets, the number of unexpected components was different from zero, indicating that the "second-order advantage" was still necessary due to two related reasons: (1) the spectral characteristics of the test samples were usually different from those samples used in the calibration and validation sets; (2) the selected algorithm uses an incomplete calibration [42].

Satisfactory results were obtained for all the analytes as it can be noticed in Table 3 .

Average interval LOD values calculated as it has been proposed by Allegrini and Olivieri [58] were obtained for carbaryl, carbendazim, and thiabendazole, where $\mathrm{LODs}_{\min }=2.5,4.0$, and $1.4 \mu \mathrm{g} \cdot \mathrm{L}^{-1}$ corresponding to 0.050 , 0.080 , and $0.028 \mathrm{mg} \cdot \mathrm{kg}^{-1}$ and $\mathrm{LODs}_{\max }=5.0,7.0$, and $3.9 \mu \mathrm{g} \cdot \mathrm{L}^{-1}$ corresponding to $0.100,0.140,0.078 \mathrm{mg} \cdot \mathrm{kg}^{-1}$, respectively, in banana samples; meanwhile, LODs $\mathrm{Lin}_{\min }$ values of $2.8,4.5$, and $1.8 \mu \mathrm{g} \cdot \mathrm{L}^{-1}$ corresponding to $0.056,0.090$, and $0.036 \mathrm{mg} \cdot \mathrm{kg}^{-1}$ and $\mathrm{LODs}_{\max }=5.4,7.6$, and $4.0 \mu \mathrm{g} \cdot \mathrm{L}^{-1}$ corresponding to $0.108,0.152$, and $0.080 \mathrm{mg} \cdot \mathrm{kg}^{-1}$ were 
TABLE 2: Maximum residue limits for different official organisms: comparison with LODs of the present method.

\begin{tabular}{|c|c|c|c|c|c|c|}
\hline \multirow{2}{*}{ Legislation } & \multicolumn{3}{|c|}{ MRLs banana $\mathrm{mg} \cdot \mathrm{kg}^{-1}$} & \multicolumn{3}{|c|}{ MRLs orange $\mathrm{mg} \cdot \mathrm{kg}^{-1}$} \\
\hline & Carbaryl & Carbendazim & Thiabendazole & Carbaryl & Carbendazim & Thiabendazole \\
\hline SENASA (Argentine) & - & $\begin{array}{c}\mathrm{W}: 1 \\
\mathrm{P}: 0.2\end{array}$ & $\begin{array}{l}\mathrm{W}: 3 \\
\mathrm{P}: 0.4\end{array}$ & 3 & $\begin{array}{l}\mathrm{W}: 5 \\
\mathrm{P}: 1\end{array}$ & 10 \\
\hline Codex Alimentarius (FAO; OMS) & - & $\begin{array}{l}W: 1 \\
P: 0.2\end{array}$ & 5 & 15 & 1 & 7 \\
\hline$E P A / U S A$ & 10 & $\begin{array}{c}\mathrm{W}: 1 \\
\mathrm{P}: 0.2\end{array}$ & $\begin{array}{l}W: 3 \\
P: 0.4\end{array}$ & 10 & 10 & 7 \\
\hline European Union Commission & $0.05-1^{* *}$ & $0.1-1^{* *}$ & 6 & $0.01-0.05$ & 0.2 & 7 \\
\hline$L O D^{* *}$ & $\begin{array}{l}0.038 \\
0.088\end{array}$ & $\begin{array}{l}0.054 \\
0.120\end{array}$ & $\begin{array}{l}0.018 \\
0.056\end{array}$ & $\begin{array}{l}0.044 \\
0.088\end{array}$ & $\begin{array}{l}0.072 \\
0.144\end{array}$ & $\begin{array}{l}0.020 \\
0.060\end{array}$ \\
\hline
\end{tabular}

-: no MRL value established for pesticide, where an MRL column contains no data, the particular data source either does not recognize this as an independent crop type, or no information is available. Usually, in this case, a "default value" is assigned corresponding to the limit of detection of the reference method (0.01-0.05 mg.kg $\left.{ }^{-1}\right)$ or another legislation is considered like EPA or EU. ${ }^{* *} 0.05$ and $0.1 \mathrm{mg} \cdot \mathrm{kg}^{-1}$ correspond to the EU harmonized value. This implies that the EU member and nonmember states (Norway and Switzerland) recognize the harmonized level as the import tolerance. Where the nonmember states have a higher level as import tolerance, the value applied as MRL in both cases is $1 \mathrm{mg} \mathrm{kg}^{-1}$ [60]. ** Limit of detection of the minimum and maximum values of the present proposed method in the presence of matrix background. $\mathrm{W}=$ whole fruit; $\mathrm{P}=$ peeled fruit.

TABLE 3: Calibration in presence of matrix: test sample analysis applying U-PLS/RBL and evaluation of method determination stage.

\begin{tabular}{|c|c|c|c|c|c|c|c|c|}
\hline \multicolumn{3}{|c|}{ Carbaryl $\mu \mathrm{g} \cdot \mathrm{L}^{-1 \dagger}$} & \multicolumn{3}{|c|}{ Carbendazim $\mu \mathrm{g} \cdot \mathrm{L}^{-1 \dagger}$} & \multicolumn{3}{|c|}{ Thiabendazole $\mu \mathrm{g} . \mathrm{L}^{-1 \dagger}$} \\
\hline Added & $\begin{array}{c}\text { Found } \\
\text { banana }^{\dagger}\end{array}$ & Found orange $^{\dagger}$ & Added & Found banana $^{\dagger}$ & Found orange ${ }^{\dagger}$ & Added & Found banana $^{\dagger}$ & Found orange $^{\dagger}$ \\
\hline 50 & $43.1(2)$ & $44.1(2)$ & 0 & $7-1(3)$ & $6(2)$ & 30 & $30.1(2)$ & $26.1(1)$ \\
\hline 20 & $26.0(1)$ & $17.0(2)$ & 20 & $23.0(4)$ & $21(1)$ & 0 & $0(2)$ & $1.1(1)$ \\
\hline 30 & $33.2(2)$ & $24.2(1)$ & 30 & $36.2(2)$ & $36(1)$ & 20 & $22.1(1)$ & $19.1(1)$ \\
\hline 50 & $50.3(2)$ & $54.1(1)$ & 40 & $38.3(3)$ & $44(1)$ & 40 & $38.2(2)$ & $36.4(2)$ \\
\hline 30 & $30.4(3)$ & $33.0(1)$ & 0 & $5.0(4)$ & $2(1)$ & 30 & $27.3(3)$ & $26.3(1)$ \\
\hline 0 & $3.1(2)$ & $1.1(1)$ & 0 & $4.1(4)$ & $2(4)$ & 0 & $1.1(1)$ & $2.1(2)$ \\
\hline 20 & $18.2(1)$ & $22,2(1)$ & 30 & $39.0(5)$ & $29(3)$ & 20 & $22.2(9)$ & $21.1(3)$ \\
\hline 15 & $15.1(1)$ & $16.1(1)$ & 0 & $7.1(2)$ & $7(4)$ & 20 & $19.0(1)$ & $22.2(2)$ \\
\hline 70 & $71.0(1)$ & $72.0(2)$ & 40 & $40.1(3)$ & $43(3)$ & 0 & $0(1)$ & $1.1(2)$ \\
\hline 70 & $67.7(1)$ & $68.2(2)$ & 70 & $62.2(4)$ & $70(3)$ & 20 & $25.1(2)$ & $17,4(3)$ \\
\hline 60 & $59.1(2)$ & $58.3(3)$ & 60 & $52.1(4)$ & $63(4)$ & 30 & $30.2(2)$ & $27.0(2)$ \\
\hline 60 & $53.0(2)$ & $56.1(2)$ & 50 & $57.0(3)$ & $54(4)$ & 30 & $31.3(2)$ & $32.1(2)$ \\
\hline 40 & $40.1(2)$ & $42.1(4)$ & 0 & $6.0(5)$ & $6(2)$ & 30 & $25.1(11)$ & $28.2(3)$ \\
\hline$R M S E P \mu \mathrm{g} \cdot \mathrm{L}^{-1}$ & 3.6 & 3.3 & & 6.1 & 4.1 & & 2.3 & 2.6 \\
\hline$R E P \%$ & 3.0 & 2.8 & & 5.2 & 3.5 & & 1.9 & 2.2 \\
\hline \multirow{2}{*}{$L O D \mu \mathrm{g} \cdot \mathrm{L}^{-1}$} & 2.5 & 2.8 & & 4.0 & 4.5 & & 1.4 & 1.8 \\
\hline & 5.0 & 5.4 & & 7.0 & 7.6 & & 3.9 & 4.0 \\
\hline \multirow{2}{*}{$L O D \mathrm{mg} \cdot \mathrm{kg}^{-1}$} & 0.050 & 0.056 & & 0.080 & 0.090 & & 0.028 & 0.036 \\
\hline & 0.100 & 0.108 & & 0.140 & 0.152 & & 0.078 & 0.080 \\
\hline $\operatorname{SEN}$ AFU $\left(\mu \mathrm{g} \cdot \mathrm{L}^{-1}\right)^{-1}$ & 2.1 & 1.8 & & 1.9 & 1.7 & & 7.8 & 7.4 \\
\hline$\gamma \mathrm{L} \mu \mathrm{g}^{-1}$ & 0.7 & 0.6 & & 0.6 & 0.5 & & 2.0 & 1.8 \\
\hline$\gamma^{-1} \mu \mathrm{g} \cdot \mathrm{L}^{-1}$ & 1.4 & 1.7 & & 1.6 & 1.8 & & 0.5 & 0.6 \\
\hline
\end{tabular}

RMSEP = root mean square error of prediction. REP $\%=$ relative error of prediction. ${ }^{\dagger}$ Predicted concentrations, averages of triplicate analysis. Standard deviation in parenthesis. Latent variables for U-PLS $A=4$ for all the analytes. Unexpected components $N_{\text {unx }}$ for stabilizing U-PLS residuals $s_{u} N_{\text {unx }}=1$ or $N_{\text {unx }}$ $=2$ or $N_{\mathrm{unx}}=3$ depending on fruits samples. $L O D$ calculated as an interval [58] SEN = Sensitivity expressed as the ratio between the arbitrary units of fluorescence and concentration (corresponding to the net signal of the analyte at unit concentration; $\gamma=$ analytical sensitivity calculated as the ratio between the sensitivity (SEN) and the instrumental noise level; $\gamma^{-1}=$ inverse of analytical sensitivity is the minimum concentration difference which can be measured).

obtained in orange samples, for carbaryl, carbendazim, and thiabendazole, respectively. Sensitivity (SEN), analytical sensitivity $\left(\gamma_{n}\right)$, and inverse of analytical sensitivity were also calculated for the analytes in both fruits (Table 3).

These figures are sample-dependent, so all these values are averages over the whole set of samples since the secondorder advantage has been applied.
It is interesting to remark that for test samples, LOD values were higher; meanwhile, SEN and analytical sensitivity values were lower than those obtained for validation samples, surely due to the presence of different potential interferent compounds not considered in the calibration set.

All these values of figures of merit were appropriate considering the calibration ranges. 
3.2.2. Spiked Real Samples: Recovery Study-Validation of the Extraction Technique and of the Whole Method. Up to this moment, the ability of the proposed method for determining the selected analytes in the complex fruit matrices, even in the presence of background interactions, strong spectral overlapping, and unexpected components spectrally active at the selected wavelength ranges, has been successfully proved.

In order to determine the ability of the whole method involving determination and extraction steps, the accuracy of the extraction technique must also be evaluated. For this purpose, prediction fruits samples free from pesticides were fortified with analytes prior to the extraction step and treated as it is described in Sections 2.3.1 and 2.4.

(1) Validation of the Extraction Technique. Analytes were extracted from these fruit samples using methanol once and then ethyl acetate and sodium sulfate in accordance with the reference extraction technique (Section 2.4). Thus, the accuracy of the proposed extraction technique was particularly validated by comparing results obtained using methanol with those obtained by using the classical extraction technique using ethyl acetate and sodium sulfate (Tables 4 and 5). Both kinds of predicted values were statistically compared by applying a paired $t$-test comparison. Calculated $t$-values of $1.68,1.35$, and 1.25 were obtained in banana samples and $1.72,1.83$, and 1.89 in orange samples, with corresponding critical tabulated $t$-values $(\alpha=0.05$ and degrees of freedom 17,17 , and 20) $=2.11,2.11$, and 2.09 for carbaryl, carbendazim, and thiabendazole, respectively. In all cases, calculated $t$-values were lower than tabulated $t$-values indicating that there is not significant statistic difference between these results; it means, results obtained applying the proposed extraction technique were statistically comparable with those obtained by using the reference extraction technique. Determination of pesticides required four latent variables for each one and $N_{\mathrm{unx}}=1,2$, and 3 depending on samples $[42,54]$.

(2) Validation of the Whole Proposed Method: Extraction Stage and Determination Stage and Recovery Study. The proposed whole method was validated performing recovery studies, comparing taken and found concentration values for each pesticide in each prediction fruit sample. Results are shown in Tables 4 and 5. Recoveries of $83 \%$ to $110 \%$ were obtained, applying four latent variables for each analyte and one, two, or three unexpected components, depending on the samples $\left(N_{\text {unx }}\right)$ as it has been discussed above $[42,54]$. In order to evaluate these results, elliptical joint confidence regions (EJCRs) were calculated for each pesticide in each fruit, indicating a good correlation between the predicted and nominal concentrations; the point $(0,1)$ was included in the ellipse in all cases (Figure 7).

3.3. Real Samples. Finally, the proposed method was applied for analyzing other fruits samples purchased in different shops in Rosario, Argentina, as it has been described in Experimental. Results are shown in Table 6. It can be noticed that carbendazim and thiabendazole in some banana samples, as well as carbaryl and thiabendazole in some orange samples, were detected at concentration levels over the detection limits (Table 6). However, fortunately, these levels were lower than the Maximum Residue Limits (MRLs) fixed by different official control organisms: SENASA (National Food Safety and Quality Service) in our country, Argentina; Codex Alimentarius considered by the Food and Agriculture Organization of the United Nations (FAO) and the World Health Organization (WHO); as well as the United State Legislation, Environmental Protection Agency (EPA) (Table 2). So, it can be concluded that selected fruits were suitable for human consumption.

On the contrary, considering the European Union Legislation, that is stricter, orange samples N1, N2, and N3 were not appropriate for consumption (Tables 2 and 6). However, these samples are in accordance with the other legislations.

Although the accuracy of the method was proved applying recovery tests (discussed earlier), in this case, it was also validated using the reference method based on HPLC (see Section 2). Results were statistically compared with those obtained by this reference method using a paired $t$-test, being the $t$-calculated value for all pesticides, in both fruits, lower than the $t$-tabulated value for the corresponding degrees of freedom and $\alpha=0.05$ (Table 6), so that it can be concluded that there is not a significant statistical difference between both results.

\section{Conclusions}

Carbendazim, carbaryl, and thiabendazole, three commonly used pesticides in fruits and vegetables, have been determined in banana and orange samples by a chemometrics-assisted spectrofluorimetric method. Emissionexcitation fluorescence matrices were obtained and treated by applying the flexible algorithm U-PLS (unfolded partial least-squares) coupled to RBL (residual bilinearization).

The presence of unexpected components, some of them natural fluorescent, in the complex matrices of fruits required higher-order data in order to achieve "the secondorder advantage"; so that second-order data as excitationemission fluorescence matrices were recorded. Moreover, analyte-background interactions as well as fluorescence inner filter effects, all samples dependent, caused a loss of trilinearity and were well resolved by U-PLS, including background signals in the calibration set. Meanwhile, RBL was able to cope with the presence of unexpected components, potentially interferents, achieving the "second-order advantage." Only a simple previous extraction with methanol was required since the potential interferents were mathematically removed by chemometrics; this extraction technique was also satisfactorily validated against a classical extraction technique based on the use of ethyl acetate and sodium sulfate. The aid of chemometrics using higher-order data also enhanced selectivity and sensitivity allowing to determine pesticides at very low concentrations, in fact the detection limits (LODs) for the three pesticides were in 
TABLE 4: Banana samples: calibration in presence of matrix-recovery study. Test sample analysis applying U-PLS/RBL. Evaluation of the whole method: extraction and determination stages.

\begin{tabular}{|c|c|c|c|c|c|c|c|c|c|c|c|}
\hline \multicolumn{12}{|c|}{ Banana samples } \\
\hline \multicolumn{4}{|c|}{ Carbaryl $\mu \mathrm{g} \cdot \mathrm{L}^{-1 \dagger}$} & \multicolumn{4}{|c|}{ Carbendazim $\mu \mathrm{g} \cdot \mathrm{L}^{-1 \dagger}$} & \multicolumn{4}{|c|}{ Thiabendazole $\mu \mathrm{g} \cdot \mathrm{L}^{-1 \dagger}$} \\
\hline Added & $\begin{array}{l}\text { Found }^{\dagger} \\
\text { M.E.T. }\end{array}$ & $\operatorname{Rec} \%$ & $\begin{array}{c}\text { Found }^{\dagger} \\
\text { R.E.T. }\end{array}$ & Added & $\begin{array}{l}\text { Found }^{\dagger} \\
\text { M.E.T. }\end{array}$ & $\operatorname{Rec} \%$ & $\begin{array}{c}\text { Found }^{\dagger} \\
\text { R.E.T. }\end{array}$ & Added & $\begin{array}{l}\text { Found }^{\dagger} \\
\text { M.E.T. }\end{array}$ & $\operatorname{Rec} \%$ & $\begin{array}{l}\text { Found }^{\dagger} \\
\text { R.E.T. }\end{array}$ \\
\hline 0 & $2.0(3)$ & & $1.0(2)$ & & & & & & & & \\
\hline 50 & $52.0(1)$ & 104 & $50.1(1)$ & & & & & & & & \\
\hline 70 & $67.0(4)$ & 96 & $69.0(1)$ & & & & & & & & \\
\hline & & & & 0 & $4(3)$ & & $2.8(1)$ & & & & \\
\hline & & & & 70 & $63.1(2)$ & 88 & $66(2)$ & & & & \\
\hline- & & & & 100 & $94.2(2)$ & 92 & $99(3)$ & & & & \\
\hline- & & & & & & & & 0 & $1.1(1)$ & & $0(1)$ \\
\hline & & & & & & & & 20 & $18.2(2)$ & 90 & $21.0(3)$ \\
\hline & & & & & & & & 30 & $31.1(2)$ & 103 & $29.8(1)$ \\
\hline & & & & & & & & 40 & $37.2(1)$ & 92 & $41.1(1)$ \\
\hline 30 & $33.1(2)$ & 110 & $34.1(1)$ & 50 & $44.2(3)$ & 88 & $47.2(1)$ & 20 & $19.2(1)$ & 95 & $21.0(1)$ \\
\hline 60 & $56.2(2)$ & 93 & $63.1(1)$ & 75 & $65.1(2)$ & 87 & $69.1(1)$ & 30 & $\begin{array}{c}27.1(2) \\
90\end{array}$ & $\begin{array}{c}29.4 \\
(2)\end{array}$ & \\
\hline 90 & $87.1(2)$ & 97 & 94.0 (1) & 100 & $92.3(2)$ & 92 & $99.2(2)$ & 40 & $\begin{array}{c}38.2(1) \\
95\end{array}$ & $43.1(1)$ & \\
\hline
\end{tabular}

${ }^{\dagger}$ Predicted concentrations, averages of triplicate analysis. Standard deviation in parenthesis. M.E.T.: methanol extraction technique. R.E.T.: reference extraction technique. Latent variables for U-PLS $A=4$ for all the analytes. Unexpected components $N_{\text {unx }}$ for stabilizing U-PLS residuals $s_{u} N_{\text {unx }}=1$ or $N_{\text {unx }}=2$ or $N_{\mathrm{unx}}=3$ depending on fruit samples.

TABLE 5: Orange samples: calibration in presence of matrix: recovery study. Test sample analysis applying U-PLS/RBL. Evaluation of the whole method: extraction and determination stages.

\begin{tabular}{|c|c|c|c|c|c|c|c|c|c|c|c|}
\hline \multicolumn{12}{|c|}{ Orange samples } \\
\hline \multicolumn{4}{|c|}{ Carbaryl $\mu \mathrm{g} \cdot \mathrm{L}^{-1 \dagger}$} & \multicolumn{4}{|c|}{ Carbendazim $\mu \mathrm{g} \cdot \mathrm{L}^{-1 \dagger}$} & \multicolumn{4}{|c|}{ Thiabendazole $\mu \mathrm{g} \cdot \mathrm{L}^{-1 \dagger}$} \\
\hline Added & $\begin{array}{l}\text { Found }^{\dagger} \\
\text { M.E.T. }\end{array}$ & $\operatorname{Rec} \%$ & $\begin{array}{c}\text { Found }^{\dagger} \\
T\end{array}$ & Added & $\begin{array}{l}\text { Found }^{\dagger} \\
\text { M.E.T. }\end{array}$ & $\operatorname{Rec} \%$ & $\begin{array}{c}\text { Found }^{\dagger} \text { R.E. } \\
\text { T. }\end{array}$ & Added & $\begin{array}{c}\text { Found }^{\dagger} \text { M.E. } \\
T .\end{array}$ & $\operatorname{Rec} \%$ & $\begin{array}{c}\text { Found }^{\dagger} \text { R.E. } \\
\text { T. }\end{array}$ \\
\hline 0 & $1.1(3)$ & & $1.0(2)$ & & & & & & & & \\
\hline 50 & $4.04(1)$ & 88 & $52.0(1)$ & & & & & & & & \\
\hline \multirow[t]{3}{*}{75} & $71.1(4)$ & 96 & $76.0(1)$ & & & & & & & & \\
\hline & & & & 0 & $5.0(2)$ & & $3.7(1)$ & & & & \\
\hline & & & & 70 & $64.0(1)$ & 91 & $66.3(2)$ & & & & \\
\hline- & & & & 100 & $92.2(4)$ & 92 & $98.5(1)$ & & & & \\
\hline \multirow[t]{4}{*}{-} & & & & & & & & 0 & $1.1(1)$ & & $0(1)$ \\
\hline & & & & & & & & 20 & $18.2(2)$ & 88 & $21.2(3)$ \\
\hline & & & & & & & & 30 & $26.3(2)$ & 87 & $27.1(1)$ \\
\hline & & & & & & & & 40 & $37.4(1)$ & 93 & $41.2(1)$ \\
\hline 30 & $26.1(3)$ & 88 & $33.2(2)$ & 50 & $49.0(3)$ & 98 & $51.1(1)$ & 20 & $17.0(1)$ & 86 & $21.1(1)$ \\
\hline 60 & $56.4(1)$ & 93 & $59.4(3)$ & 70 & $62.1(2)$ & 89 & $69.0(1)$ & 30 & $27.2(2)$ & 90 & $29.3(2)$ \\
\hline 90 & $82.3(4)$ & 91 & $86.2(1)$ & 100 & $92.2(2)$ & 92 & $98.2(2)$ & 40 & $37.4(1)$ & 93 & $38.1(1)$ \\
\hline
\end{tabular}

${ }^{\dagger}$ Predicted concentrations, averages of triplicate analysis. Standard deviation in parenthesis. M.E.T.: methanol extraction technique. R.E.T.: reference extraction technique. Latent variables for U-PLS $A=4$ for all the analytes. Unexpected components $N_{\mathrm{unx}}$ for stabilizing U-PLS residuals $s_{u} N_{\mathrm{unx}}=1$ or $N_{\mathrm{unx}}=2$ or $N_{\mathrm{unx}}=3$ depending on fruit samples.

accordance with the Maximum Residuals Limits (MRLs) fixed by national and international legislations. Satisfactory results were obtained for artificially spiked samples proving the accuracy by recovery tests. Real samples were also analyzed and results were statistically comparable with those obtained applying a reference method based on highperformance liquid chromatography (HPLC).

The present method could be suitable for quality control in food analysis and an alternative for routine laboratories, since it requires much simple and cheap equipment and 


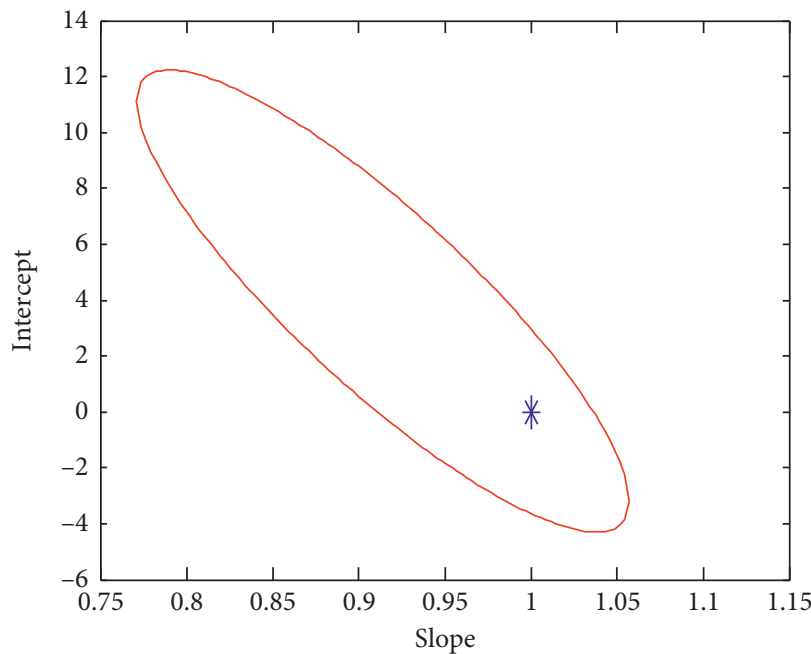

(a)

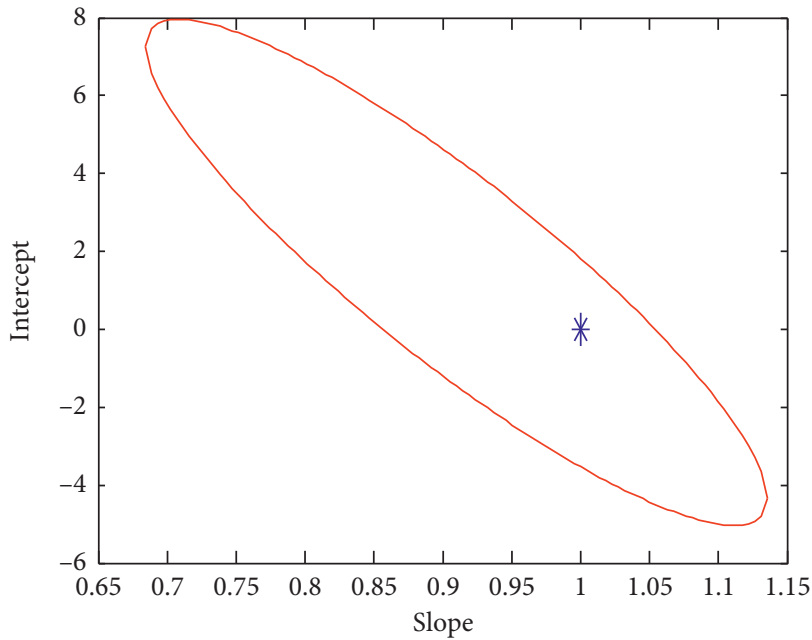

(c)

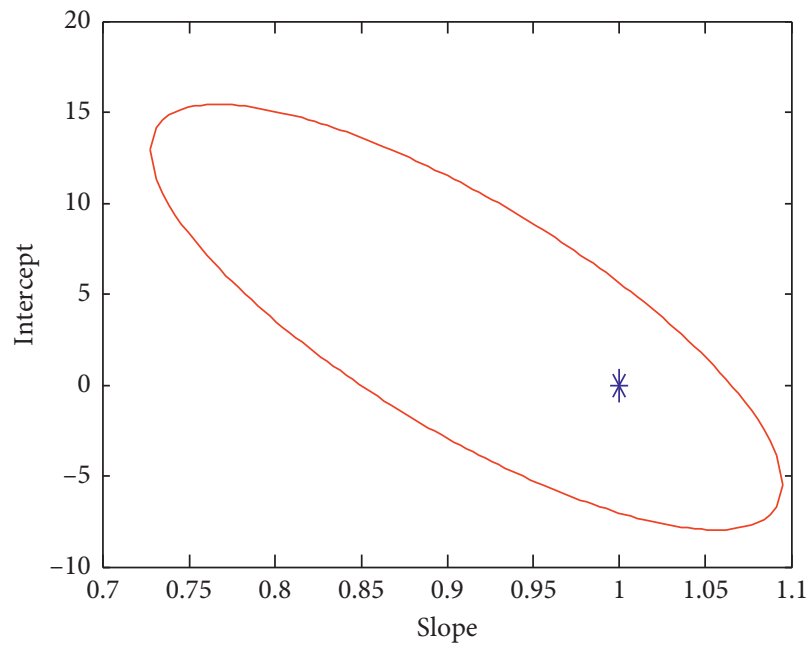

(e)

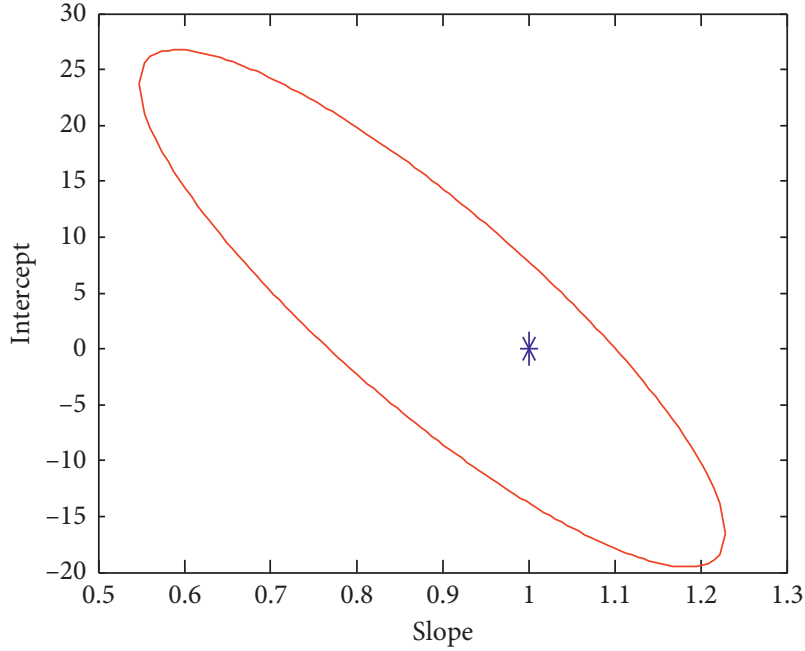

(b)

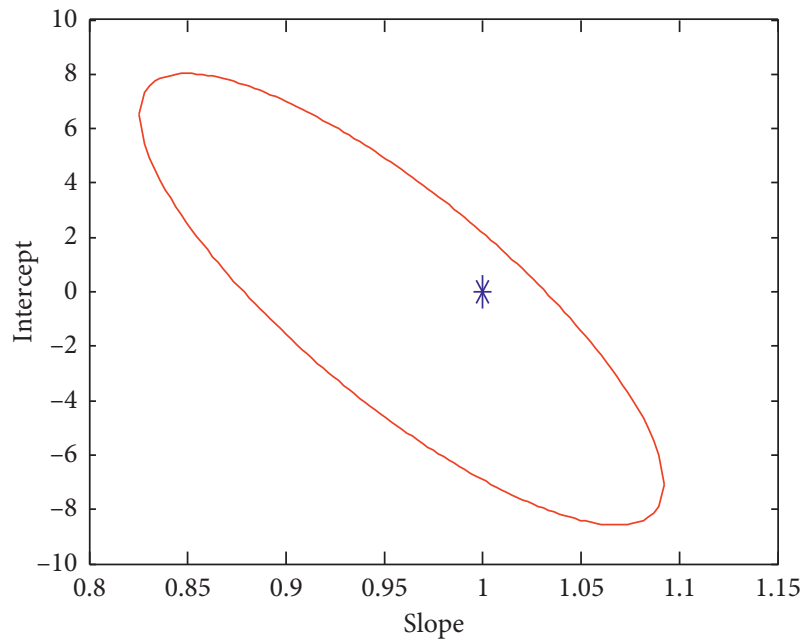

(d)

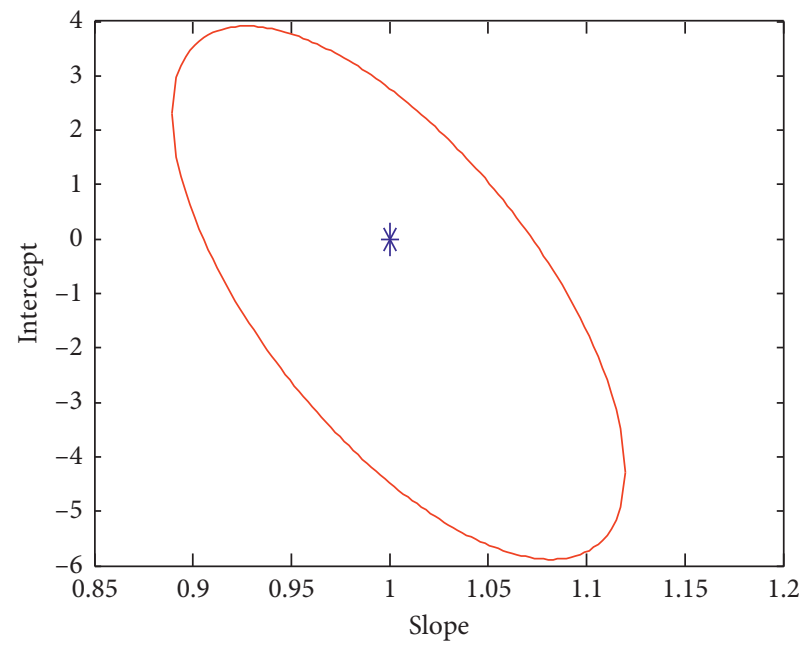

(f)

FIGURE 7: Elliptical joint confidence regions for recovery studies (nominal versus predicted concentration). (a), (b), and (c) correspond to carbaryl, carbendazim, and thiabendazole in banana; (d), (e), and (f) correspond to carbaryl, carbendazim, and thiabendazole in orange. 
TABLE 6: Calibration in presence of matrix: real sample analysis by applying methanolic extraction and UPLS/RBL. Comparison with a reference method based on HPLC being: calculated $t$-values $=1.48$, degrees of freedom $n=13$, and the corresponding tabulated critical $t$ values $=2.16(\alpha=0.05 / 2)$.

Carbaryl $^{\dagger}$

Thiabendazole ${ }^{\dagger \S}$

Samples Proposed method Reference method $\begin{gathered}\text { Proposed } \\ \text { method }\end{gathered}$ Reference method Proposed method Reference method

\begin{tabular}{|c|c|c|c|c|c|c|c|c|c|}
\hline & $\mu \mathrm{g} \cdot \mathrm{L}^{-1}$ & $\mathrm{mg} \cdot \mathrm{kg}^{-1}$ & $\mathrm{mg} \cdot \mathrm{kg}^{-1}$ & $\mu \mathrm{g} \cdot \mathrm{L}^{-1}$ & $\mathrm{mg} \cdot \mathrm{kg}^{-1}$ & $\mathrm{mg} \cdot \mathrm{kg}^{-1}$ & $\mu \mathrm{g} \cdot \mathrm{L}^{-1}$ & $\mathrm{mg} \cdot \mathrm{kg}^{-1}$ & $\mathrm{mg} \cdot \mathrm{kg}^{-1}$ \\
\hline B1 & - & - & - & - & - & - & $4.1(1)$ & 0.076 & 0.070 \\
\hline B2 & - & - & - & $4.0(1)$ & 0.080 & 0.087 & $7.0(2)$ & 0.14 & 0.13 \\
\hline B3 & - & - & - & $5.1(1)$ & 0.100 & 0.090 & $4.0(2)$ & 0.080 & 0.089 \\
\hline B4 & - & - & - & - & - & - & - & - & - \\
\hline B5 & - & - & - & $6.0(1)$ & 0.120 & 0.112 & $4.1(1)$ & 0.080 & 0.091 \\
\hline N1 & $10.1(1)$ & 0.200 & 0.189 & - & - & - & - & - & - \\
\hline N2 & $15.3(3)$ & 0.300 & 0.330 & - & - & - & - & - & - \\
\hline N3 & $5.2(1)$ & 0.100 & 0.110 & - & - & - & $1.1(1)$ & 0.018 & 0.025 \\
\hline N4 & $1.1(1)$ & 0.018 & 0.024 & - & - & - & $24.0(2)$ & 0.480 & 0.500 \\
\hline
\end{tabular}

${ }^{\dagger}$ Average of three determinations. Standard deviation in parenthesis obtained by three replicate analyses. $N_{\mathrm{u}}$ : number of unexpected components (1 to 3 ) depending on samples. ${ }^{S}$ Predicted concentration values statistically compared with HPLC values for all pesticides in both fruits, applying paired $t$-test: being: calculated $t$-values $=1.48$, degrees of freedom $n=13$; and the corresponding tabulated critical $t$-values $=2.16(\alpha=0.05 / 2)$.

avoids the use of high amount of environmental contaminants, in comparison with chromatographic methods.

\section{Data Availability}

The data used to support the findings of this study are available from the corresponding author upon request.

\section{Additional Points}

Highlights. (i) A chemometric-assisted spectrofluorimetric method was developed for determining pesticides in fruits, (ii) a simple extraction technique based only in the used of methanol was applied, (iii) the model involved inner filter effects, background interactions, strong spectral overlapping, and unexpected components, (iv) second-order data were obtained, resolved by second-order algorithms, (v) best results were obtained applying unfolded partial least-squares coupled to residual bilinearizarion, (vi) the flexibility of U-PLS could cope with matrix effects, resolving the trilinearity lost including matrix background in the calibration set, and (vii) "second-order advantage" achieved by residual bilinearization allowed pesticide determination even in the presence of unexpected components.

\section{Conflicts of Interest}

The authors declare that they have no conflicts of interest.

\section{Acknowledgments}

The authors thank the National University of Rosario, Faculty of Biochemical and Pharmaceutical Sciences, Rosario, Argentina (Projects BIO 253 and BIO 415) and Argentine Catholic University, Faculty of Chemistry and Engineering, Rosario, Argentina, for financial support. CONICET (National Centre of Scientific and Technical Research) and ANPCyT (National Agency of Scientific and
Technological Promotion) are also acknowledged for financial support. The authors also gratefully thank Prof. Dr. Alejandro C. Olivieri, internationally recognized for his experience in chemometric analysis, for his helpful collaboration in the present work.

\section{Supplementary Materials}

This section consists of a brief discussion of the theory related to the chemometric tools used in the present work, including (1) data orders; (2) algorithms 2.1 U-PLS (unfolded partial least-squares), and 2.2 U-PLS/RBL (unfolded partial least-squares coupled to residual bilinearization); and (3) figures of merit and a list of references useful for obtaining more information about these themes. (Supplementary Materials)

\section{References}

[1] C. K. Winter and E. A. Jara, "Pesticide food safety standards as companions to tolerances and maximum residue limits," Journal of Integrative Agriculture, vol. 14, no. 11, pp. 23582364, 2015.

[2] J. Fenik, M. Tankiewicz, and M. biziuk, "Properties and determination of pesticides in fruits and vegetables," $\operatorname{Tr} A C$ Trends in Analytical Chemistry, vol. 30, no. 6, pp. 814-826, 2011.

[3] J. N. Seiber, "Modern issues in food safety-a perspective," Journal of Integrative Agriculture, vol. 11, no. 1, pp. 9-13, 2012.

[4] A. Farag, H. Ebrahim, R. ElMazoudy, and E. Kadous, "Developmental toxicity of fungicide carbendazim in female mice," Birth Defects Research Part B: Developmental and Reproductive Toxicology, vol. 92, no. 2, pp. 122-130, 2011.

[5] M. Valckea, M. H. Bourgaulta, L. Rochettea et al., "Human health risk assessment on the consumption of fruits and vegetables containing residual pesticides: a cancer and noncancer risk/benefit perspective," Environment International, vol. 108, pp. 63-74, 2017.

[6] US Environmental Protection Agency Office of Pesticide Programs Chemicals Evaluated for Carcinogenic Potential Annual Cancer Report 2017. USEPA Office of Pesticide 
Programs, Health Effects Division, Science Information Management Branch: Chemicals Evaluated for Carcinogenic Potential, https://www.epa.gov/pesticide-tolerances, https:// www.epa.gov/risk/guidelines-carcinogen-risk-assessment.

[7] G. Eisenbrand, O. Ungerer, and R. Preussmann, "The reaction of nitrite with pesticides. II. Formation, chemical properties and carcinogenic activity of the $\mathrm{N}$-nitroso derivative of $\mathrm{N}$ methyl-1-naphthyl carbamate (carbaryl)," Food and Cosmetics Toxicology, vol. 13, no. 3, pp. 365-367, 1975.

[8] Thiabendazole, Liver Tox, National Institutes of Health and U.S. Department of Health and Human Services, USA, https:// livertox.nlm.nih.gov//Thiabendazole.htm.

[9] Occupational Safety and Health Administration, USA, https:// www.osha.gov/dts/chemicalsampling/data/CH_271570.html.

[10] National Food Safety and Quality Service, SENASA, Argentina, http://www.senasa.gob.ar.

[11] Codex Alimentarius International, http://www.fao.org/faowho-codexalimentarius/codex-texts/dbs/pestres/pesticides/en/, http://www.codexalimentarius.net, http://www.fao.org/faowho-codexalimentarius/es, http://www.fao.org/fao-whocodexalimentarius/index.

[12] Z. Cheng, F. Dong, J. Xu et al., "Simultaneous determination of organophosphorus pesticides in fruits and vegetables using atmospheric pressure gas chromatography quadrupole-timeof-flight mass spectrometry," Food Chemistry, vol. 231, pp. 365-373, 2017.

[13] L. Cherta, T. Portolés, J. Beltran, E. Pitarch, J. G. Mol, and F. Hernández, "Application of gas chromatography-(triple quadrupole) massspectrometry with atmospheric pressure chemical ionization for the determination of multiclass pesticides in fruits and vegetables," Journal of Chromatography A, vol. 1314, pp. 224-240, 2013.

[14] D. Lu, X. Qiu, C. Feng et al., "Simultaneous determination of 45 pesticides in fruit and vegetable using an improved QuEChERS method and on-line gel permeation chromatography-gas chromatography/mass spectrometer," Journal of Chromatography B, vol. 895-896, pp. 17-24, 2012.

[15] A. Samsidar, S. Siddiquee, and S. M. Shaarani, "A review of extraction, analytical and advanced methods for determination of pesticides in environment and foodstuffs," Trends in Food Science \& Technology, vol. 71, pp. 188-201, 2018.

[16] V. Boeris, J. A. Arancibia, and A. C. Olivieri, "Determination of five pesticides in juice, fruit and vegetable samplesby means of liquid chromatography combined with multivariatecurve resolution," Analytica Chimica Acta, vol. 814, pp. 23-30, 2014.

[17] P. Sivaperumal, P. Anand, and L. Riddhi, "Rapid determination of pesticide residues in fruits and vegetables, using ultra-high-performance liquid chromatography/timeof-flight mass spectrometry," Food Chemistry, vol. 168, pp. 356-365, 2015.

[18] T. M. Rizzetti, M. Kemmerich, M. L. Martins, O. D. Prestes, M. B. Adaime, and R. Zanella, "Optimization of a QuEChERS based method by means of central composite design for pesticide multiresidue determination in orange juice by UHPLC-MS/MS," Food Chemistry, vol. 196, pp. 25-33, 2016.

[19] R. P. Carneiro, F. A. S. Oliveira, F. D. Madureira, G. Silva, W. R. de Souza, and R. Pereira Lopes, "Development and method validation for determination of 128 pesticides in bananas by modified QuEChERS and UHPLCeMS/MS analysis," Food Control, vol. 33, no. 2, pp. 413-423, 2013.

[20] L. M. Ravelo-Pérez, J. Hernández-Borges, A. Cifuentes, and M. A. Rodríguez-Delgado, "MEKC combined with SPE and sample stacking for multiple analysis of pesticides in water samples at the ng/L level," Electrophoresis, vol. 28, no. 11, pp. 1805-1814, 2007.

[21] P. Navarro, J. A. Gabaldon, A. J. Pérez, and S. Morais, "Detection of chemical residues in tangerine juices by a duplex immunoassay," Talanta, vol. 116, pp. 33-38, 2013.

[22] J. Li, J. Lu, X. Qiao, and Z. Xu, "A study on biomimetic immunoassay-capillary electrophoresis method based on molecularly imprinted polymer for determination of trace trichlorfon residue in vegetables," Food Chemistry, vol. 221, pp. 1285-1290, 2017.

[23] E. J. Llorent-Martínez, M. L. Fernández-de Córdova, A. RuizMedina, and P. Ortega-Barrales, "Fluorimetric determination of thiabendazole residues in mushrooms using sequential injection analysis," Talanta, vol. 96, pp. 190-194, 2012.

[24] E. J. Llorent-Martínez, M. L. Fernández-de Córdova, A. RuizMedina, and P. Ortega-Barrales, "Automated optosensor for the determination of carbaryl residues in vegetable edible oils and table olive extracts," Journal of Food Composition and Analysis, vol. 26, no. 1-2, pp. 66-71, 2012.

[25] I. Timofeeva, A. Shishov, D. Kanashina, D. Dzema, and A. Bulatov, "On-line in syringe sugaring out liquid-liquid extraction coupled with HPLC-MS/MS for the determination of pesticides in fruit and berry juices," Talanta, vol. 167, pp. 761-767, 2017.

[26] Y. Farina, M. P. Abdullah, N. Bibi, and W. M. A. W. M. Khalik, "Determination of pesticide residues in leafy vegetables at parts per billion levels by a chemometric study using GC-ECD in Cameron Highlands, Malaysia," Food Chemistry, vol. 224, pp. 55-61, 2017.

[27] X. Yang, H. Zhang, and Y. Liu, "Multiresidue method for determination of 88 pesticides in berry fruits using solidphase extraction and gas chromatography-mass spectrometry: determination of 88 pesticides in berries using SPE and GC-MS," Food Chemistry, vol. 127, no. 2, pp. 855-865, 2011.

[28] M. Radisic, S. Grujić, T. Vasiljević, and M. Laušević, "Determination of pesticides by matrix solid-phase dispersion and liquid chromatography-tandem mass spectrometry," Food Chemistry, vol. 113, no. 2, pp. 712-719, 2009.

[29] E. H. da Costa Morais, C. Hollingworth Collins, and I. C. Sales Fontes Jardim, "Pesticide determination in sweet peppers using QuEChERS and LC-MS/MS," Food Chemistry, vol. 249, pp. 77-83, 2018.

[30] M. S. Viera, T. M. Rizzetti, M. P. de Souza et al., "Multiresidue determination of pesticides in crop plants by the quick, easy, cheap, effective, rugged, and safe method and ultra-highperformance liquid chromatography tandem mass spectrometry using a calibration based on a single level standard addition in the sample," Journal of Chromatography A, vol. 1526, pp. 119-127, 2017.

[31] Z. Chengzhou, Y. Guohai, L. He, D. Dan, and L. Yuehe, "Electrochemical sensors and biosensors based on nanomaterials and nanostructures," Analytical Chemistry, vol. 87, no. 1, pp. 230-249, 2015.

[32] X. Yan, H. Li, X. Han, and X. Su, "A ratiometric fluorescent quantum dots based biosensor for organophosphorus pesticides detection by inner-filter effect," Biosensors and Bioelectronics, vol. 74, pp. 277-283, 2015.

[33] R. Rapini and G. Marrazza, "Chapter 1-biosensor potential in pesticide monitoring," in Comprehensive Analytical Chemistry, vol. 74, pp. 3-31, Elsevier, Amsterdam, Netherlands, 2016.

[34] A. Valero-Navarro, P. C. Damiani, J. F. Fernández-Sánchez, A. Segura-Carretero, and A. Fernández-Gutiérrez, "Chemometric-assisted MIP-optosensing system for the 
simultaneous determination of monoamine naphthalenes in drinking waters," Talanta, vol. 78, no. 1, pp. 57-65, 2008.

[35] J. B. Addison, G. P. Semeluk, and I. Unger, "The luminescence properties of pesticides Fluorescing and phosphorescing carbamates," Journal of Luminescence, vol. 15, no. 3, pp. 323-339, 1977.

[36] J. R. Lakowicz, Principles of Fluorescence Spectroscopy, Springer, New York, NY, USA, 2006.

[37] J. Aimo, E. Promancio, and P. C. Damiani, "Determination of reducing sugars in foodstuff applying multivariate secondorder calibration," Analytical Methods, vol. 8, no. 23, pp. 4617-4631, 2016.

[38] R. Bro, "Multivariate calibration: what is in chemometrics for the analytical chemist?," Analytica Chimica Acta, vol. 500, no. 1-2, pp. 185-194, 2003.

[39] J. H. Kalivas, "Multivariate calibration, an overview," Analytical Letters, vol. 38, no. 14, pp. 2259-2279, 2005.

[40] A. C. Olivieri, H. C. Goicoechea, and F. A. Iñon, "MVC1: an integrated MatLab toolbox for first-order multivariate calibration," Chemometrics and Intelligent Laboratory Systems, vol. 73, no. 2, pp. 189-197, 2004.

[41] G. M. Escandar, H. C. Goicoechea, A. Muñoz De La Peña, and A. C. Olivieri, "Second- and higher-order data generation and calibration: a tutoria," Analytica Chimica Acta, vol. 806, pp. 8-26, 2014.

[42] A. Olivieri and G. Escandar, Practical Three Way Calibration, Elsevier Inc., Cambridge, UK, 2014.

[43] H. Wu, Y. Li, and R. Yu, "Recent developments of chemical multiway calibration methodologies with second order or higher-order advantages," Journal of Chemometrics, vol. 28, no. 5, pp. 476-489, 2014.

[44] G. N. Piccirilli and G. M. Escandar, "Partial least-squares with residual bilinearization for the spectrofluorimetric determination of pesticides. A solution of the problems of innerfilter effects and matrix interferents," Analyst, vol. 131, no. 9, pp. 1012-1020, 2006.

[45] L. Rubio, L. A. Sarabia, and M. C. Ortiz, "Standard addition method based on four-way PARAFAC decomposition to solve the matrix interferences in the determination of carbamate pesticides in lettuce using excitation-emission fluorescence data," Talanta, vol. 138, pp. 86-99, 2015.

[46] S.-H. Zhu, H.-L. Wu, A.-L. Xia, Q.-J. Han, and Y. Zhang, "Determination of carbendazim in bananas by excitationemission matrix fluorescence with three second-order calibration methods," Analytical Sciences, vol. 23, no. 10, pp. 1173-1177, 2007.

[47] D. Bohoyo Gil, A. Muñoz de la Peña, J. A. Arancibia, G. M. Escandar, and A. C. Olivieri, "Second-order advantage achieved by unfolded-partial least-squares/residual bilinearization modeling of excitation-emission fluorescence data presenting inner filter effects," Analytical Chemistry, vol. 78, no. 23, pp. 8051-8058, 2006.

[48] P. C. Damiani, "Determination of atenolol in human urine by emission-excitation fluorescence matrices and unfolded partial least-squares with residual bilinearization," Talanta, vol. 85, no. 3, pp. 1526-1534, 2011.

[49] G. M. Escandar and A. C. Olivieri, "A road map for multi-way calibration models,” Analyst, vol. 142, no. 16, pp. 2862-2873, 2017.

[50] D. C. Montgomery, Design and Analysis of Experiments, John Wiley \& Sons, Inc., Hoboken, NJ, USA, 8th edition, 2013.

[51] J. F. Magallanes and A. C. Olivieri, "The effect of factor interactions in Plackett-Burman experimental designs. Comparison of Bayesian-Gibbs analysis and genetic algorithms,"
Chemometrics and Intelligent Laboratory Systems, vol. 102, no. 1, pp. 8-14, 2010.

[52] The Mathworks, MATLAB 7.0, The Mathworks, Natick, MA, USA, 2007.

[53] A. C. Olivieri, H.-L. Wu, and R.-Q. Yu, “MVC2: a MATLAB graphical interface toolbox for second-order multivariate calibration," Chemometrics and Intelligent Laboratory Systems, vol. 96, no. 2, pp. 246-251, 2009.

[54] D. M. Haaland and E. V. Thomas, "Partial least-squares methods for spectral analyses. 1. Relation to other quantitative calibration methods and the extraction of qualitative information," Analytical Chemistry, vol. 60, no. 11, pp. 1193-1202, 1988.

[55] J. W. Batista Braga, R. L. Carneiro, and R. J. Poppi, "Evaluation of the number of factors needed for residual bilinearization in BLLS and UPLS models to achieve the secondorder advantage," Chemometrics and Intelligent Laboratory Systems, vol. 100, no. 2, pp. 99-109, 2010.

[56] A. C. Olivieri, N. M. Faber, J. Ferré, R. Boqué, J. Kalivas, and H. Mark, "Uncertainty estimation and figures of merit for multivariate calibration (IUPAC technical report)," Pure and Applied Chemistry, vol. 78, no. 3, pp. 633-661, 2006.

[57] A. C. Olivieri, "Analytical figures of merit from univariate to multivariate calibration," Chemical Reviews, vol. 114, no. 10, pp. 5358-5378, 2014.

[58] F. Allegrini and A. C. Olivieri, "IUPAC-consistent approach to the limit of detection in partial least- squares calibration," Analytical Chemistry, vol. 86, no. 15, pp. 7858-7866, 2014.

[59] EUR-lex, Access to European Union Law and Related Documents, http://eur-lex.europa.eu/legal-content/, https://eurlex.europa.eu/homepage.html.

[60] Bananas MRL Datasheet, absi. Agri Business Systems International, https://www.nda.agric.za/doaDev/sideMenu/ foodSafety/doc/Bananas\%20MRL\%20Datasheet.pdf. 

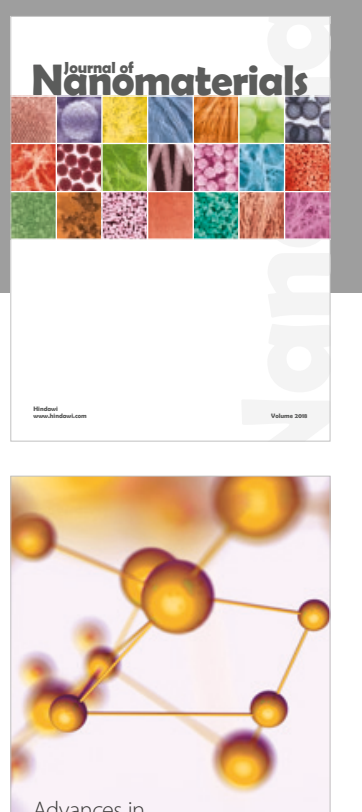

Physical Chemistry
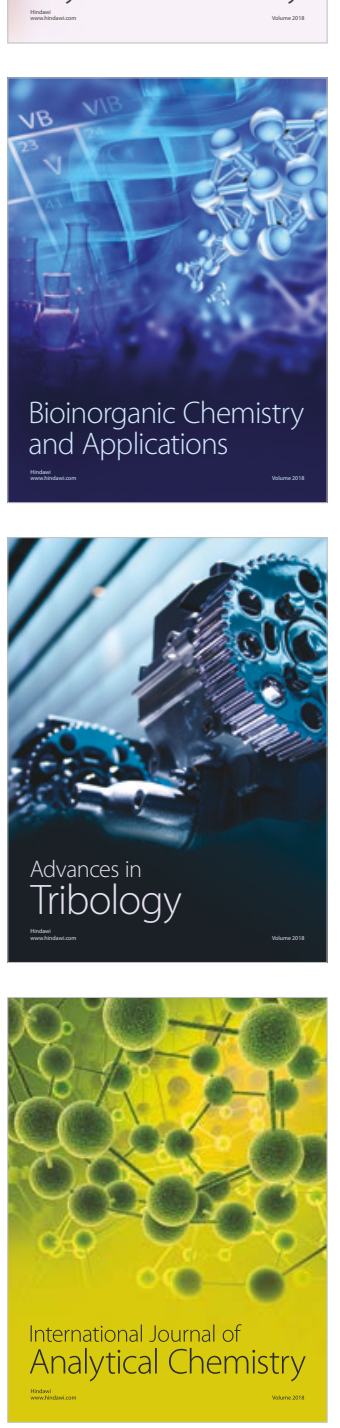

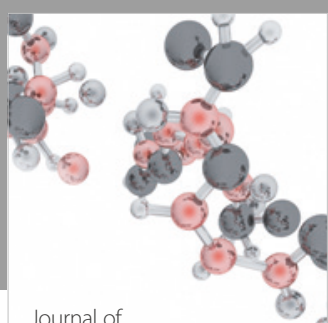

Analytical Methods

in Chemistry

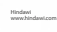

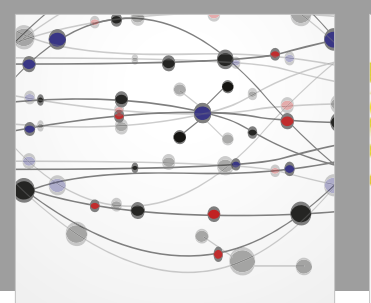

The Scientific World Journal

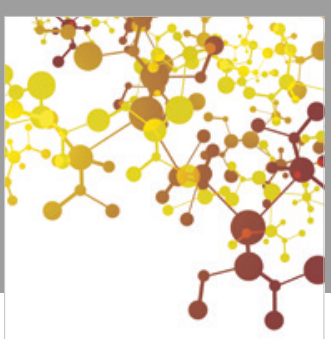

Journal of

Applied Chemistry
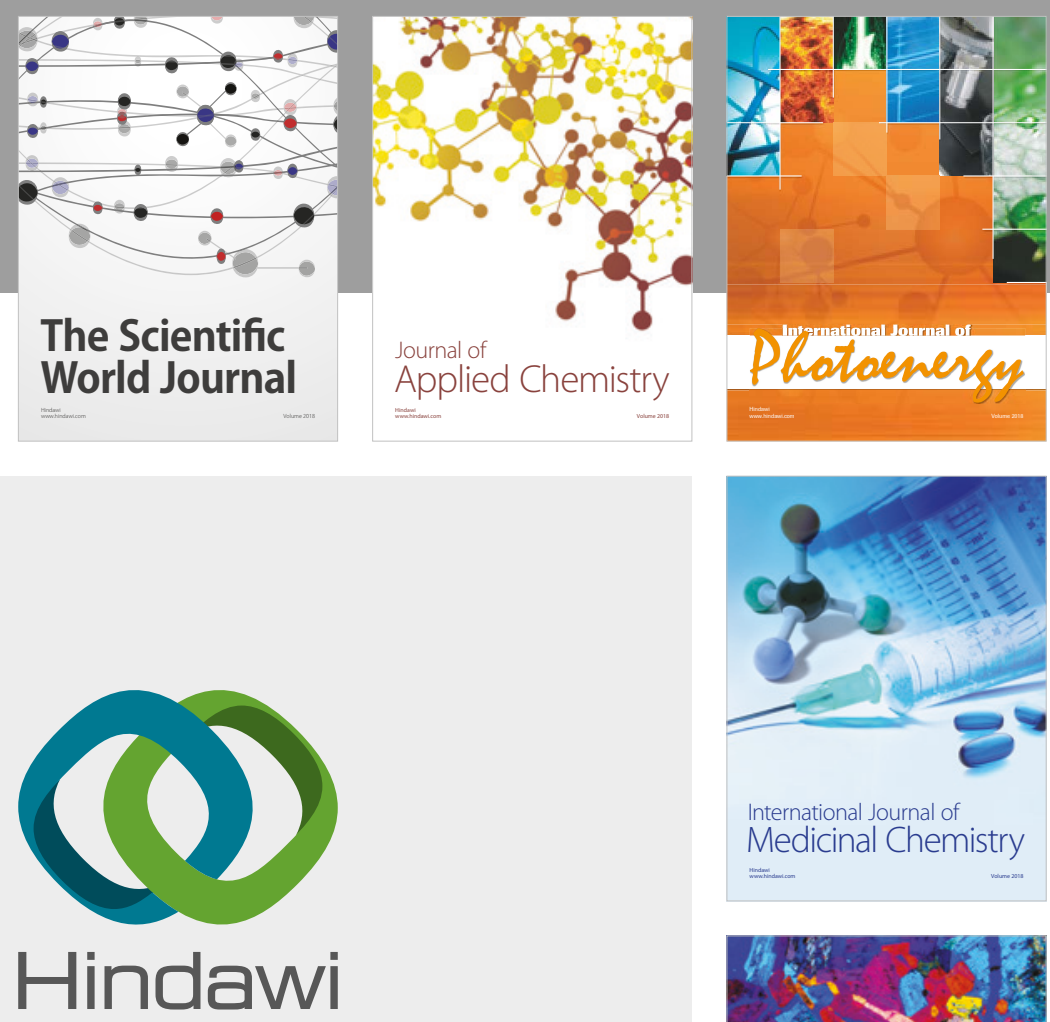

Submit your manuscripts at

www.hindawi.com
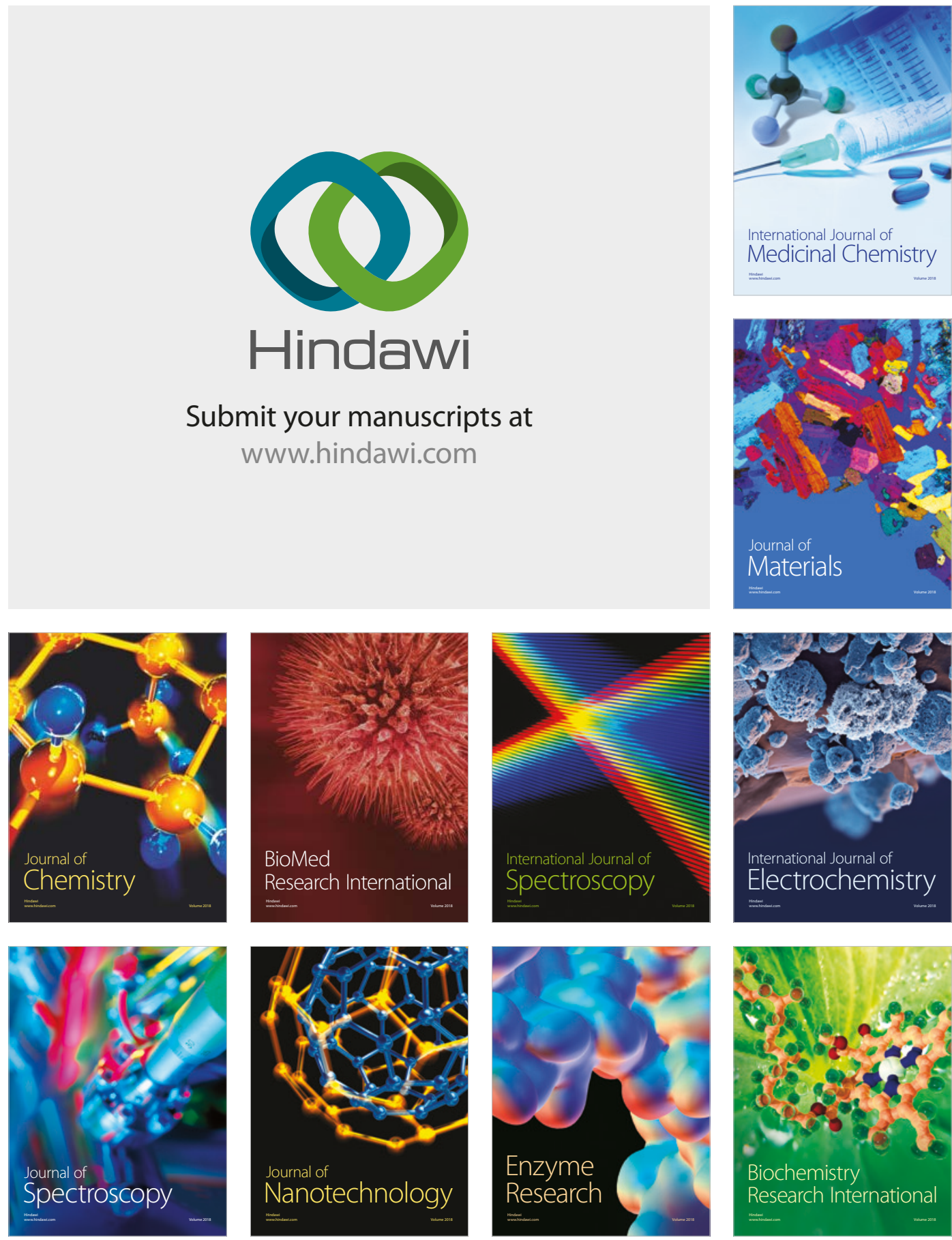
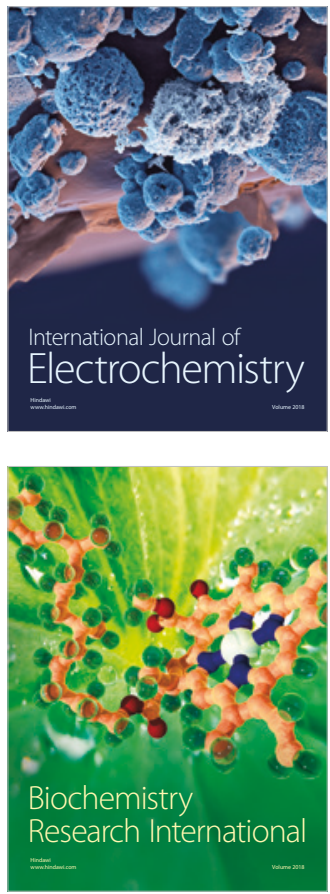